\title{
Modern Aspects of the Smiles Rearrangement
}

DOI:

10.1002/chem.201700353

\section{Document Version}

Accepted author manuscript

Link to publication record in Manchester Research Explorer

\section{Citation for published version (APA):}

Holden, C., \& Greaney, M. (2017). Modern Aspects of the Smiles Rearrangement. Chemistry: A European Journal, 23, 8992-9008. https://doi.org/10.1002/chem.201700353

\section{Published in:}

Chemistry: A European Journal

\section{Citing this paper}

Please note that where the full-text provided on Manchester Research Explorer is the Author Accepted Manuscript or Proof version this may differ from the final Published version. If citing, it is advised that you check and use the publisher's definitive version.

\section{General rights}

Copyright and moral rights for the publications made accessible in the Research Explorer are retained by the authors and/or other copyright owners and it is a condition of accessing publications that users recognise and abide by the legal requirements associated with these rights.

\section{Takedown policy}

If you believe that this document breaches copyright please refer to the University of Manchester's Takedown Procedures [http://man.ac.uk/04Y6Bo] or contact uml.scholarlycommunications@manchester.ac.uk providing relevant details, so we can investigate your claim.

\section{OPEN ACCESS}




\section{Modern Aspects of the Smiles Rearrangement}

Catherine M. Holden and Michael F. Greaney*[a]

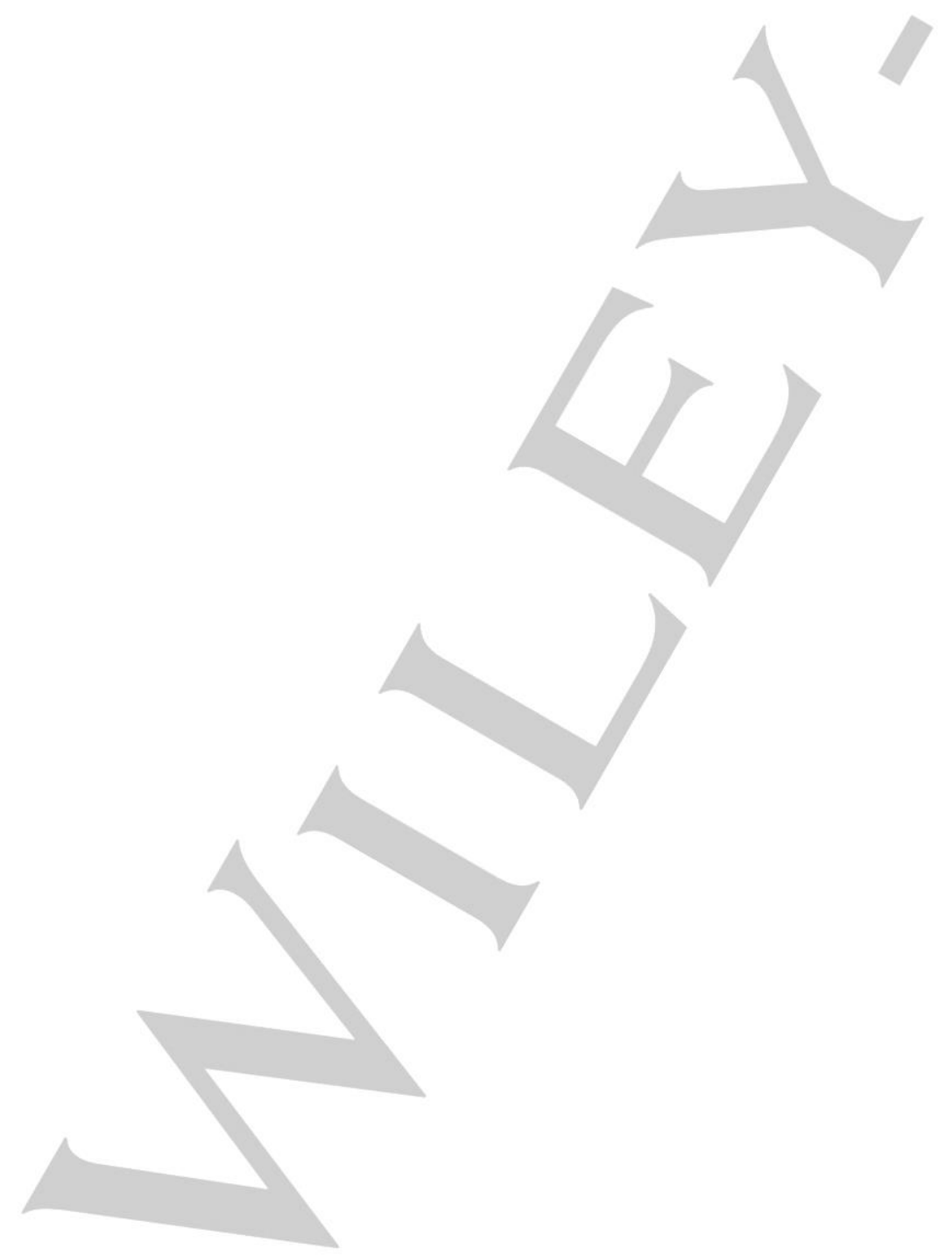


Abstract: The Smiles rearrangement is an intramolecular $\mathrm{S}_{\mathrm{N}} \mathrm{Ar}$ reaction, breaking a $\mathrm{C}-\mathrm{X}$ single bond and forming a new $\mathrm{C}-\mathrm{X}$ or $\mathrm{C}-\mathrm{C}$ bond though ipso substitution. Its vast scope, in terms of nucleophile, leaving group, and ring-size of the transition state, make it a powerful tool for arene functionalization, as it can be employed strategically to switch easily-forged bonds with more difficult connections that would be challenging to realize in the intermolecular mode.

The reaction has received significantly renewed attention in recent years, as advances in areas such as arene $\mathrm{C}-\mathrm{X}$ bond formation and radical generation have been harnessed for new arene syntheses via Smiles chemistry. In addition, new reaction modes have been discovered such as the Clayden rearrangement of lithiated ureas, creating innovative applications for Smiles rearrangements in asymmetric arylation. This minireview will discuss advances in these areas in the recent literature, covering both two-electron, polar Smiles rearrangements along with single electron radical transformations.

\section{Introduction}

The Smiles rearrangement - intramolecular migration of an aryl ring acting as an electrophile - is an old reaction which has undergone a vigorous revival in recent years for the synthesis of valuable arene and heteroarene molecules (Scheme 1). A tremendously versatile reaction, it enables the functionalization of (hetero)aromatic rings across a very broad substrate scope, often under simple and economic reaction conditions. The reaction was originally reported in 1894 by Henriques, ${ }^{[1]}$ and then by Hinsberg, ${ }^{[2]}$ for naphtholsulfones. Subsequently, the nature and generality of the reaction was determined by Smiles in a series of papers published in the 1930s. ${ }^{[3]}$ Several factors were considered key for rearrangement: the activation of the aromatic ring, the nucleofugality of the leaving group and the nucleophilicity of the entering group.

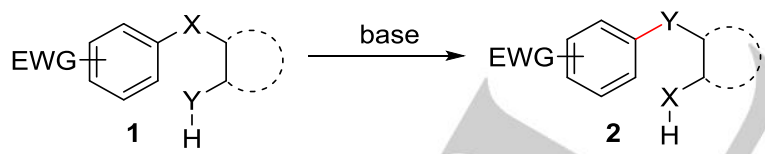

Scheme 1. Generalized Smiles rearrangement. $Y=$ nucleophile, $X=$ leaving group.

Historically, strongly electron-withdrawing nitro groups were primarily used to activate the migrating aromatic, although $p$ sulfonyl, naphthyl, 2-pyridyl and anthraquinones were also demonstrated to be capable of migration. A comprehensive monograph, which outlines the functionality then reported to activate the migrating aromatic ring and the conditions required to achieve migration, was published in 1970 by Truce and coworkers, ${ }^{[4]}$ and further reviews have appeared on aspects of Smiles chemistry in the ensuing years. ${ }^{[5]}$ Truce developed the carbanion Smiles rearrangement using a lithium base, which was effective for unactivated arenes 3 (Scheme 2); ${ }^{[6]}$ this carbon-carbon bond formation is now commonly termed the Truce-Smiles rearrangement.

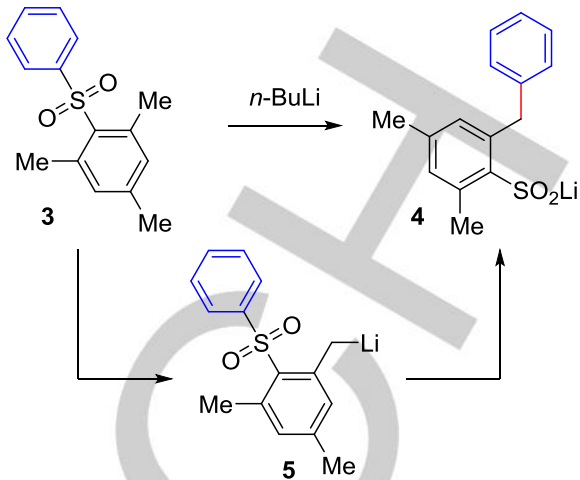

Scheme 2 The Truce-Smiles rearrangement

The effects of the entering $(Y)$ and leaving $(X)$ group are intertwined. Early studies with diaryl compounds determined that increased nucleophilicity of $Y$ facilitated the use of poorer leaving groups $X^{[3 b]}$ The deprotonation of the nucleophile has also been found to be significant in determining the outcome of a rearrangement (vide infra). As substitution of $Y$ affects both the nucleophilicity and $\mathrm{p} K_{\mathrm{a}}$, whilst enhancing nucleophilicity will facilitate deprotonation of the Meisenheimer intermediate (vide infra), a stable conjugate base of $Y$ may be unable to perform the nucleophilic attack. ${ }^{[3 \mathrm{e}]}$

The carbon linkage between the nucleophile and leaving group also exerts an influence upon the reaction, and can be manipulated to promote the rearrangement through ThorpeIngold effects (e.g. amide 6 in Scheme 3) ${ }^{[7],[8]}$<smiles>COc1ccc(NC(=O)C(C)(O)O)cc1</smiles>

Scheme 3. Use of the Thorpe-Ingold effect.

The mechanism of the Smiles rearrangement is thought to proceed via an anionic sigma complex - the Meisenheimer intermediate 9. This has been characterized by UV-Vis and NMR spectroscopy in a number of studies, ${ }^{[9,10]}$ with an example shown in Scheme 4. ${ }^{[11]}$ The spiro-intermediates were confirmed by UV-Vis spectroscopy for each substrate 11-14, and the rate of Smiles rearrangement was found to depend upon the collapse of this intermediate, The rate of rearrangement decreases in the order of $14>13>12>11$, and the rate of formation of the anionic $\sigma$-complex decreases in the order of $11,13>14>12$.

[a] Ms C. Holden and Prof M. F. Greaney

University of Manchester

Oxford Rd, Manchester, M13 9PL, UK

E-mail: michael.greaney@manchester.ac.uk 


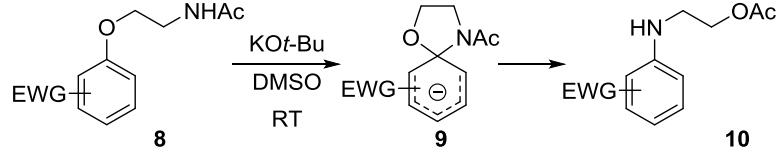
observed: UV, ${ }^{1} H$ NMR<smiles>O=C([O-])NCCOc1ccc([N+](=O)[O-])cc1[N+](=O)[O-]</smiles>

11<smiles>CNCCOc1ccc([N+](=O)[O-])cc1Br</smiles>

12<smiles>N#Cc1cc([N+](=O)[O-])ccc1OCCNCCN</smiles>

13<smiles>CCCCCCNCCOc1ccc([N+](=O)[O-])nc1</smiles>

14
Scheme 4 The effect of ring electronics on the Smiles rearrangement.

2-( $p$-Nitrophenoxy) ethylamines $\mathbf{1 5}$ have been used to study the rate of Smiles rearrangement with respect to $\mathrm{pH}$ (Scheme 5). ${ }^{[12]}$ Rate were found to be linearly dependent on $\left[\mathrm{OH}^{-}\right]$below $0.01 \mathrm{M}$ but insensitive to $\left[\mathrm{OH}^{-}\right]$above $0.1 \mathrm{M}$ where it approached a maximum. It was concluded that at low base concentration the rate determining step is deprotonation of the Meisenheimer intermediate $\mathbf{1 6}$ and only at high concentration the formation of intermediate becomes rate limiting. This contrasts with earlier work, where it was assumed that the ability of a substrate to undergo a Smiles rearrangement primarily depended solely upon the electrophilicity of the ipso-carbon. N-Alkylation was also observed to accelerate the formation of the spirointermediate due to increased nucleophilicity. ${ }^{[13]}$ Further evidence that the rate of Smiles rearrangement is determined by the collapse of the Meisenheimer intermediate was provided by substrate $\mathrm{R}=\mathrm{CH}_{2} \mathrm{CH}_{2} \mathrm{NH}_{2}$, for which intramolecular protontransfer should render the rearrangement insensitive to general base catalysis and exhibit the rate limit even at low concentrations of the base. ${ }^{[14]}$ Specific base catalysis and a $\mathrm{pH}$ insensitive rate-plateau were observed, although the rate limit was again observed at high $\mathrm{pH}$. These results corroborate the previously gathered evidence that Smiles rearrangement is dependent upon the collapse of the Meisenheimer intermediate (via deprotonation) at low base concentrations.<smiles>[R]NCCOc1ccc([N+](=O)[O-])cc1</smiles>

15<smiles>[R]C=CC1CCCC12OCCNN2[R]</smiles>

16

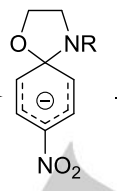

17

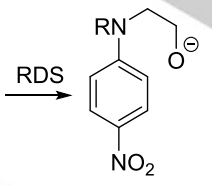

18
Scheme 5 Formation and collapse of the Meisenheimer intermediate.

Whilst the Smiles rearrangement was once characterized by the migration of nitroarenes between oxygen, nitrogen and sulfur, the scope of the rearrangement has now expanded to encompass electronically varied aromatic rings and is achieved through an interesting variety of reaction conditions. This minireview will concentrate on recent developments in the Smiles rearrangement; the reaction can proceed through both one and two electron pathways, and we will organize the review accordingly. Further, the transformation bifurcates between arene migration to a carbon or a heteroatom terminus, leading to carbon-carbon or carbon-heteroatom bond formation, respectively.
Catherine Holden received her undergraduate degree in chemistry from the University of Oxford, completing her final year in the group of Prof. Michael Willis. She then joined the research group of Prof. Michael Greaney to undertake her $\mathrm{PhD}$ at the University of Manchester, working on aryne chemistry and Truce-Smiles rearrangements.

Prof. Michael Greaney took his chemistry degree at the University of Oxford, completing his part II research project in the group of Prof. Sir Jack Baldwin in 1996. He then moved to London to carry out PhD work with Prof. William Motherwell at UCL, followed by postdoctoral work with Prof. Jeffrey Winkler at the University of Pennsylvania as a GlaxoWellcome fellow. He returned to the UK in early 2002, to a lectureship position at the University of Edinburgh, and in 2011 moved to the University of Manchester to a personal chair in organic chemistry. His laboratory focusses on new synthetic methods for organic chemistry.

\section{Two Electron Smiles Rearrangement}

\section{$2.1 C-X$ bond formation}

The classical Smiles rearrangement in which an electron deficient aromatic ring migrates from one heteroatom to another is primarily driven by the formation of a more stable anion. This anion can then be trapped and the transformation has been used to prepare a multitude of heterocyclic compounds through multicomponent, domino and cascade processes. A notable development in recent years has been the incorporation of Smiles rearrangements into transition metal-catalyzed sequences.

\subsubsection{In combination with transition metal catalysis}

Snieckus observed an unanticipated Smiles rearrangement during a domino copper iodide catalyzed synthesis of tricyclic dibenzoxazepinones $\mathbf{2 1}$ (Scheme 6) from 2-iodobenzamides and 2-bromophenols. ${ }^{[15]}$ The substitution patterns of the isolated products indicated that a rearrangement of the phenolic arene had occurred prior to a second, Ullman-type annulation. Little to no activation of the migrating ring with electron withdrawing groups was required, and electron rich aromatics also rearranged. The Snieckus group then developed an equivalent transition metal free process from 2-fluorobenzamides, which proceeded via an $\mathrm{S}_{N} \mathrm{Ar} / \mathrm{Smiles} / \mathrm{S}_{N} \mathrm{Ar}$ cascade process. ${ }^{[16]}$ No migration of electron-rich or electron-neutral arenes were reported in this case and exceedingly high temperatures were required $\left(220^{\circ} \mathrm{C}\right)$, but the reaction times were reasonable $(2 \mathrm{~h})$. 


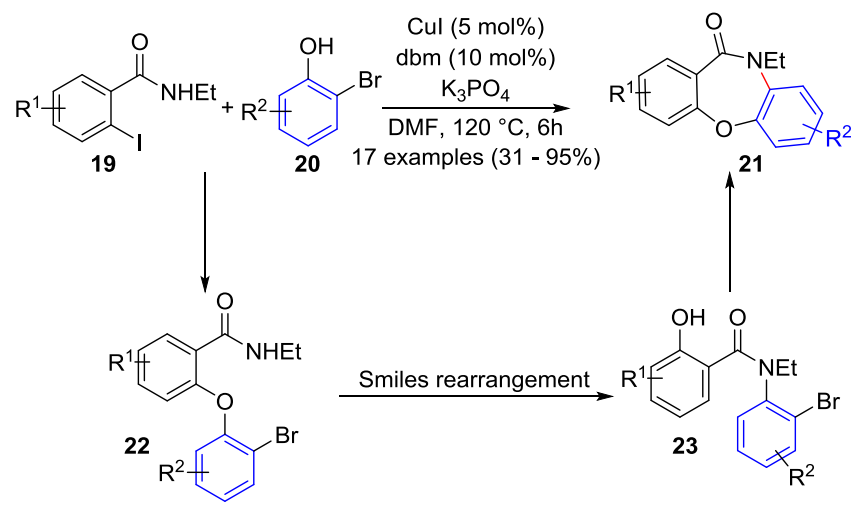

Selected examples<smiles>CCN1C(=O)c2ccc(N3CCOCC3)cc2Oc2cc(Cl)ccc21</smiles><smiles>CCN1C(=O)c2ccc(C)cc2Oc2c(C)cccc21</smiles><smiles>CCN1C(=O)c2ccc(C)cc2Oc2ncccc21</smiles>

Scheme 6. A Smiles rearrangement / interrupted copper-catalyzed domino preparation of dibenzoxazepinones. $\mathrm{Dbm}=$ dibenzoylmethane.

Ganguly et al. described a similar copper-catalyzed cross coupling/rearrangement/cyclization process to afford dibenzoxazepinones 26 in the pyridyl series (Scheme 7). ${ }^{[17]}$ Electron rich, neutral and heterocyclic rings were well tolerated, and removable groups could be used to protect the nitrogen atom.
24<smiles>O=C(N[PH2+])c1cccnc1Cl</smiles><smiles>[X]c1cc[R]c(O)c1[X]</smiles>

25
$\mathrm{Cu}_{2} \mathrm{O}(5 \mathrm{~mol} \%)$

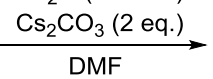

$120{ }^{\circ} \mathrm{C}, 3-10 \mathrm{~h}$ 16 examples (35-93\%)

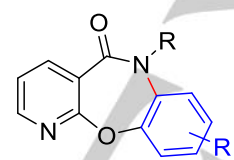

26
Scheme 7. A "ligandless" copper catalyzed domino preparation of dibenzoxazepinones.

Zhu used a reagent-controlled Smiles rearrangement to access different regioisomers of dibenzoxazepinones (Scheme 8). ${ }^{[18]}$ Amide 27, containing the Daugulis quinoline auxiliary, enabled copper catalyzed $\mathrm{C}-\mathrm{H}$ etherification followed by Goldberg coupling to afford a single regioisomeric product 29.

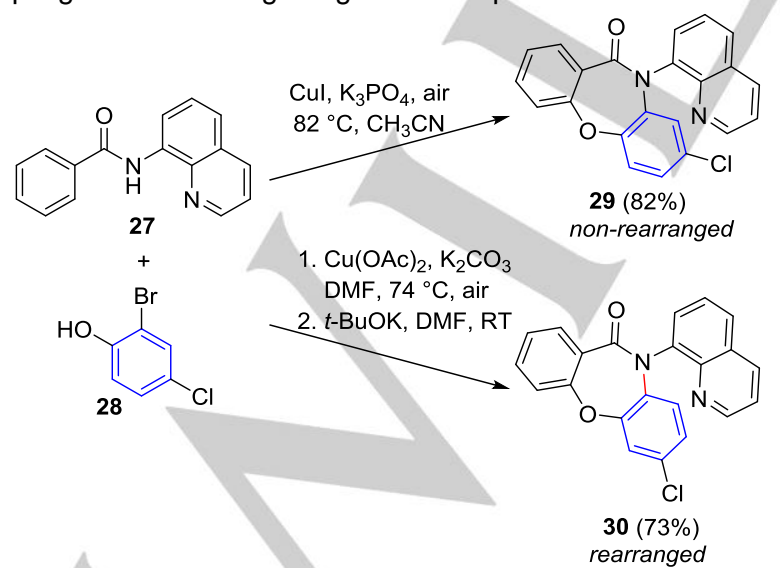

Scheme 8. Switchable Smiles rearrangement to accesses regioisomeric dibenzoxazepinones.

Alternatively, $\mathrm{C}-\mathrm{H}$ etherification and $t$-BuOK promoted Smiles rearrangement, followed by cyclization cleanly afforded the regioisomeric product $\mathbf{3 0}$. An initial reversal in selectivity had been observed following a catalyst switch from $\mathrm{Cu}_{2}(\mathrm{OH})_{2} \mathrm{CO}_{3}$ (non-rearranged) to $\mathrm{Cu}(\mathrm{OAc})_{2}$ (rearranged); this was then optimized to the final conditions using a strong base. Only 2 bromo-4-chlorophenol $\mathbf{2 8}$ was demonstrated to participate in both the rearrangement and non-rearranged transformation.

Ullman coupling/rearrangement/cyclization cascades are not limited to benzamides and Zhang et al. reported a related reaction with 2-arylindole $\mathbf{3 1}$ to afford a penta-cyclic ring system 33 as a single regioisomer (Scheme 9). ${ }^{[19]}$ A range of halogenated phenols $\mathbf{3 2}$ were used for the rearrangement and a single halogen is sufficient for activation (i.e. I $90 \%$ and $\mathrm{Br} 58 \%$ ).

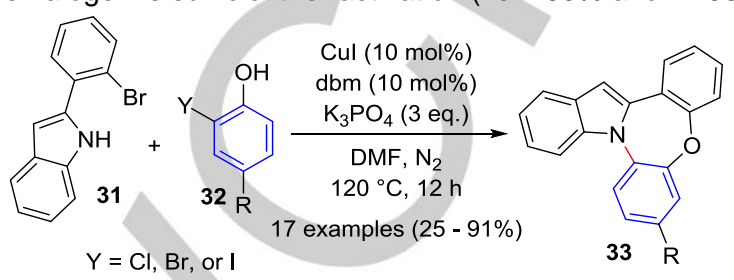

Scheme 9. A copper catalyzed one-pot synthesis of fused dibenzo[b,f][1,4]oxazepines.

\subsubsection{Miscellaneous / $N$ to $O$}

Many conventional Smiles rearrangements undergo oxygen to nitrogen migration of the arene. Recently, reversal of this reactivity has been achieved. Schnermann developed an electrophile integrating Smiles rearrangement in which a nitrogen to oxygen aryl migration occurs with C4'-O-alkyl heptamethine cyanine fluorophores 34 (Scheme 10). ${ }^{[20]}$
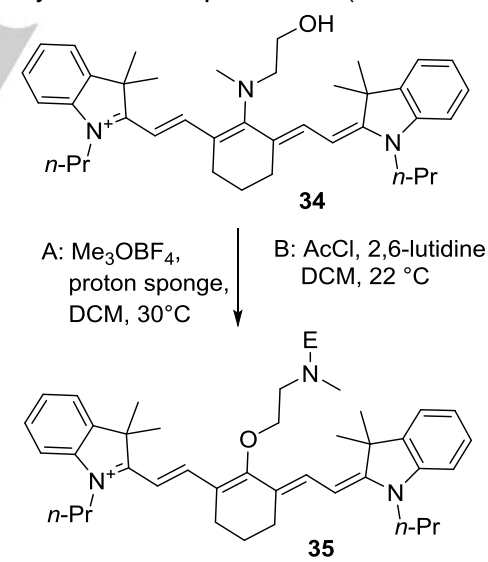

Conditions $\mathrm{A}, \mathrm{E}=\mathrm{Me}(85 \%)$

Conditions B, E = Ac (87\%)

Scheme 10. The nitrogen to oxygen transfer of a conjugated $\pi$-system.

The base promoted Smiles rearrangement was rendered irreversible through preferential trapping of the more nucleophilic amine with an electrophile. The migrating component was not an aromatic system, but rather an extended conjugated $\pi$-system. Biju and co-workers have recently reported a Smiles rearrangement in the multicomponent reaction of benzyne (from precursor 36), benzaldehyde and $\mathrm{N}, \mathrm{N}$-dimethylaniline to afford 2-aminobenzohydrol products 39 (Scheme 11). ${ }^{[21]}$ The most notable aspect of this transformation with respect to Smiles rearrangement chemistry is the unusual nitrogen to oxygen aryl migration. This is a consequence of a quaternary ammonium ion 40 which forms upon nucleophilic addition of the $\mathrm{N}, \mathrm{N}$-dimethyl aniline to benzyne. The formation of a quaternary ammonium salt is sufficient to activate the arene for rearrangement, and no additional activating substitution of the migrating aromatic is required. 


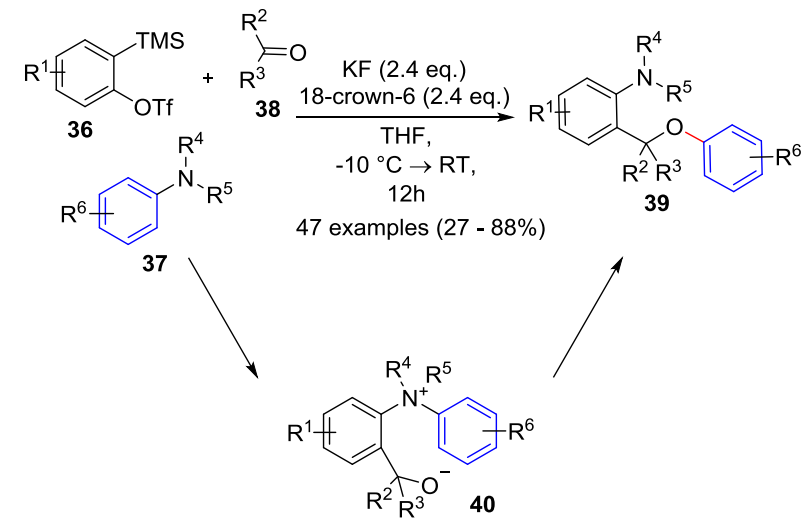

Selected examples<smiles>CCOC(=O)c1ccc(OC(c2ccc(C#N)cc2)c2ccccc2N(C)C)cc1</smiles>

$63 \%$
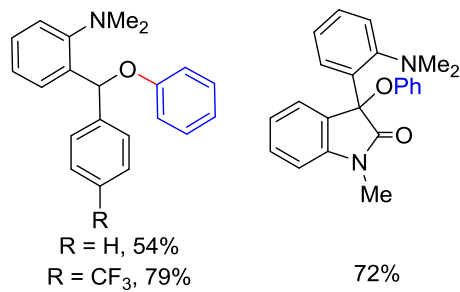

Me

$72 \%$

As with the original iMCRs, either aldehydes or imines participate leading to the Passerini-Smiles and Ugi-Smiles iMCRs respectively (Scheme 13). The El Kaïm laboratory has established both processes as powerful routes for the production of functionalized heteroaromatic amine (44, Ugi) and phenolic (45, Passerini) products with obvious relevance to medicinal chemistry. ${ }^{[23]}$

Ugi-Smiles

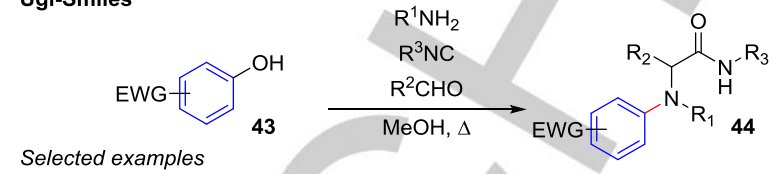

$$
\begin{aligned}
& \mathrm{X}=\mathrm{Cl}, 95 \% \\
& \mathrm{X}=\mathrm{OMe}, 62 \%, \\
& \mathrm{X}=\mathrm{Me}, 0 \%
\end{aligned}
$$

Passerini-Smiles

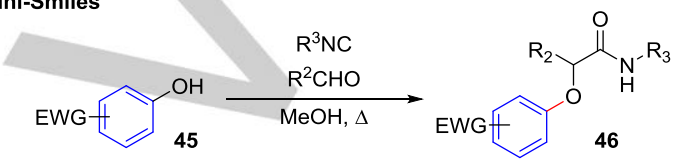

Scheme 11. A multicomponent Smiles rearrangement with an unusual $\mathrm{N}$ to $\mathrm{O}$ aryl transfer.

\subsubsection{Isocyanide Multicomponent reactions (iMCR)}

The well-known Passerini and Ugi multicomponent reactions of isocyanides with carboxylic acids and aldehydes or imines have seen extensive application to programs of combinatorial synthesis and high throughput screening. The key step in iMCR reactions involves irreversible Mumm rearrangement transferring an acyl unit from the ester group in $\mathbf{4 1}$ to the amine, driving the reaction to completion. El Kaïm and Grimaud proposed replacing the acid component in Ugi and Passerini iMCRs with a nitro-phenol, thereby utilizing a Smiles rearrangement of $\mathbf{4 2}$ as the key step (Scheme 12). ${ }^{[22]}$

Ugi Reaction

$$
\mathrm{R}^{1} \mathrm{CHO} \quad \mathrm{R}^{2} \mathrm{NH}_{2} \rightleftharpoons \mathrm{R}_{1}^{1}=\mathrm{N}_{\mathrm{R}^{2}} \stackrel{\mathrm{R}^{4} \mathrm{CO}_{2} \mathrm{H}}{\rightleftharpoons} \mathrm{R}^{1} \stackrel{\stackrel{\mathrm{H}}{\mathrm{H}} \mathrm{N}_{\mathrm{R}^{+}}^{+}}{\stackrel{+}{4} \mathrm{R}^{4} \mathrm{CO}_{2}^{-}}
$$
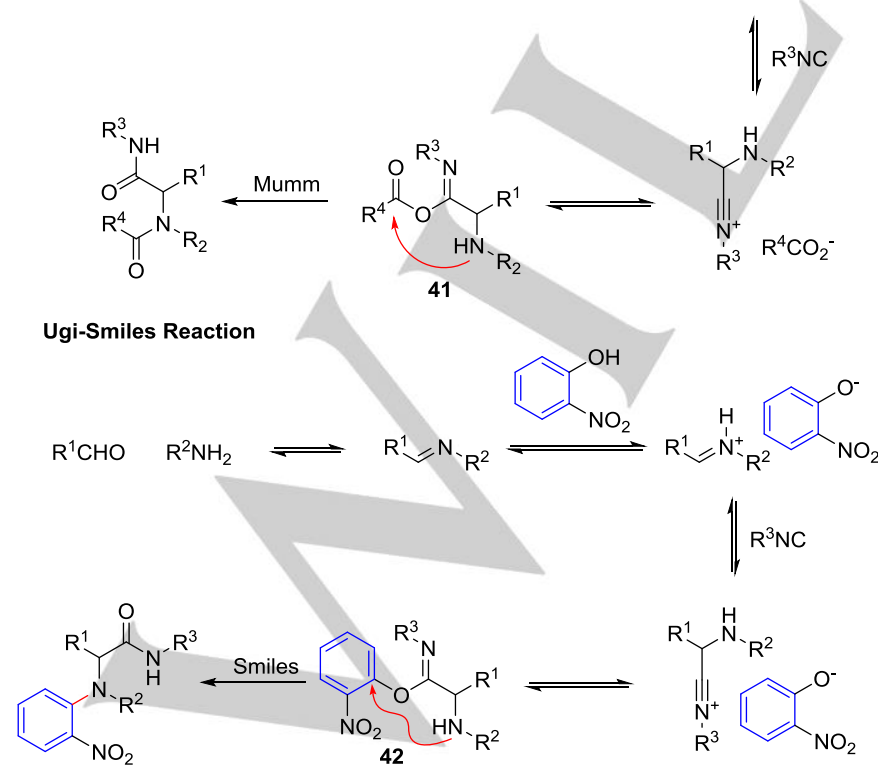

Scheme 12. A comparison of the classical Ugi and Ugi-Smiles reactions.

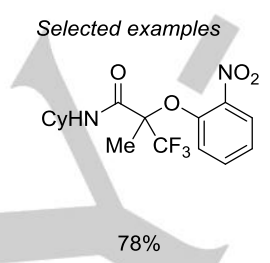

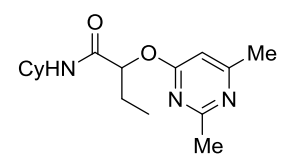

$60 \%$

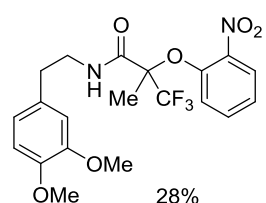

Scheme 13. The Ugi-Smiles and Passerini-Smiles reactions.

\subsubsection{Julia-Kocienski olefination}

The Smiles rearrangement is a key step of the Julia-Kocienski olefination, employing significantly milder conditions than the classical Julia-Lythgoe reaction (Scheme 14). The mechanism involves a sulfur to oxygen aryl migration of the heteroarene $\mathbf{4 8}$ (often benzothiazole (BT) or phenyltetrazole (PT)), and desulfonative elimination to provide the olefin $\mathbf{5 0}$. The procedure has been reviewed generally, ${ }^{\left[{ }^{5 d, 24]}\right.}$ and a key application is the synthesis of fluorinated olefins. ${ }^{[25]}$ Outlined below are some notable recent developments from the Jørgensen group that introduce organocatalytic processes for novel alkene and alkyne formation.

$$
\begin{aligned}
& \text { Julia-Lythgoe }
\end{aligned}
$$

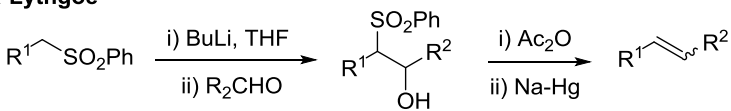

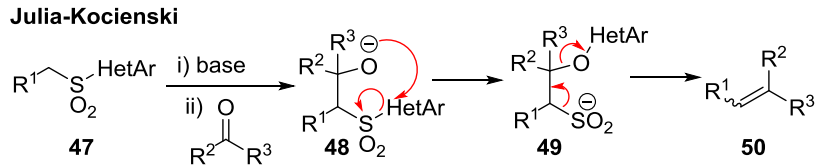

Scheme 14. Julia-Lythgoe and Julia-Kocienski olefination procedures.

Jørgensen treated $\alpha, \beta$-unsaturated aldehydes with phenyltetrazole sulfones to give adducts 53 in high ee (Scheme 15). ${ }^{[26]}$ To achieve alkenylation (conditions $A$ ), the aldehyde was first protected in acetal form followed by base promoted enolate 
formation on the ketone, then a Smiles rearrangement and elimination to afford the alkyne 54. Simple reduction of the ketone (conditions B) promoted a similar Smiles rearrangement elimination sequence affording the alkene 55 .

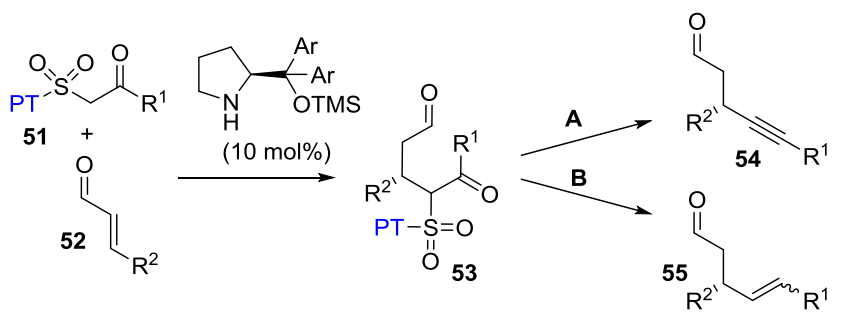

A: i) (EtO) ${ }_{3} \mathrm{CH}, p$-TSA, ii) sat. aq. $\mathrm{Na}_{2} \mathrm{CO}_{3}$, TBAl, iii) $50 \% \mathrm{TFA} / \mathrm{H}_{2} \mathrm{O}$

B: $\mathrm{NaBH}_{4}, \mathrm{MeOH}$

Scheme 15. An organocatalyzed alkynylation and alkenylation of $\alpha, \beta$ unsaturated aldehydes.

The same group used a thiourea-based catalyst to promote the enantioselective addition of $\beta$-keto benzothiazolesulfones to $\mathrm{N}$ Boc-protected imines $56 .{ }^{[27]}$ The ketone products of this organocatalyzed reaction could then be reduced, causing a Smiles rearrangement and elimination to afford enantioenriched allylic amines 58 (Scheme 16). Alternatively, the intermediates could simply be desulfonylated with no Smiles rearrangement to afford enantioenriched $\beta$-amino ketones.

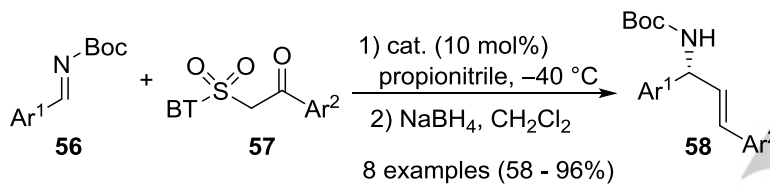

Scheme 16. Asymmetric organocatalyzed allyl amine synthesis.

The same approach with $\beta$-keto benzothiazolesulfones could be used in a formal Sonogashira reaction to afford nitro-phenyl alkynes 61 through an $S_{N} A r$ addition to arylate the sulfones (Scheme 17). ${ }^{[28]}$ The alkenylations could be performed in one pot with $\mathrm{K}_{2} \mathrm{CO}_{3}$ at $65{ }^{\circ} \mathrm{C}$, or if a brief work up was conducted after the $\mathrm{Cs}_{2} \mathrm{CO}_{3}$ mediated $\mathrm{S}_{\mathrm{N}} \mathrm{Ar}$ with $\mathrm{NaHCO}_{3}$ at $45^{\circ} \mathrm{C}$, albeit with slightly reduced yields.

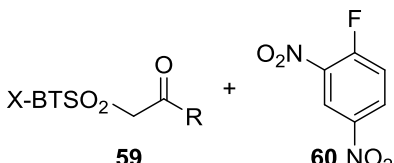

$60 \mathrm{NO}_{2}$

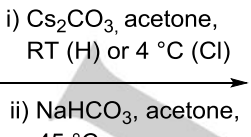
$45^{\circ} \mathrm{C}$

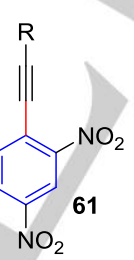

$\mathrm{X}=\mathrm{H}$ or $5-\mathrm{Cl}$

Scheme 17. Formal transition metal free Sonogashira reaction.

These transformations demonstrate that classical Smiles rearrangements which form new $\mathrm{C}-\mathrm{X}$ bonds can be used in conjunction with a diverse range of transition metal catalyzed and organocatalyzed reactions to access valuable small molecules.

\section{$2.2 C-C$ bond formation}

The first carbanion Smiles rearrangement was reported by Truce in 1958, involving rearrangement of an organolithium species (vide supra, Scheme 2) ${ }^{[6]}$ Notably, these rearrangements did not require the presence of a strongly activating group on the migrating arene. The Truce-Smiles rearrangement has been previously reviewed, ${ }^{[4,5 c]}$ here we will discuss recent developments in the literature.

\subsubsection{Phenyl ether enolate rearrangement}

Erickson and McKennon reported an unexpected phenyl ether migration via Truce-Smiles rearrangement of 2-(2pyridloxy)phenylacetic acid esters 62 , resulting in the formation of 3-pyridyl-2-benzofuranones 63 (Scheme 18). ${ }^{[29]}$ This rearrangement proceeded via a 5 -membered transition state, whilst other rearrangements for this class of substrates predominantly proceed through 6-membered transition states (vide infra).

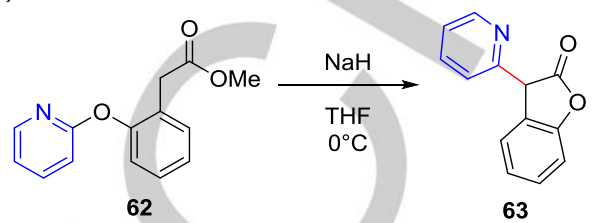

Scheme 18. Truce-Smiles rearrangement of a phenyl ether.

Keto-enolates may also participate in aryl ether rearrangements (Scheme 19). The reaction of electron deficient aryl fluorides with o-hydroxy acetophenone 65 was observed to give Carylated products 66 rather than the expected O-arylated products by Mitchell and Barvian (Scheme 19, Conditions A). ${ }^{[30]}$ The transformation was then shown to proceed at ambient temperatures in DMSO, and more fully explored with respect to compatible functionality by Snape (Scheme 19, Conditions B). ${ }^{[31]}$ However, only the 2-nitro functionality was investigated as an activating group. The process was shown to be a two-step reaction through an $\mathrm{S}_{\mathrm{N}} \mathrm{Ar} \mathrm{O}$-arylation of the acetal-protected ketone, which could then be revealed under acidic conditions, without rearrangement. This transformation was used as a key step in the preparation of the core of a 2,3,6-trisubstituted indole on large $(>50 \mathrm{~kg})$ scale by a process chemistry group led by Alorati and Gibb at Merck Sharp and Dohme. ${ }^{[32]}$

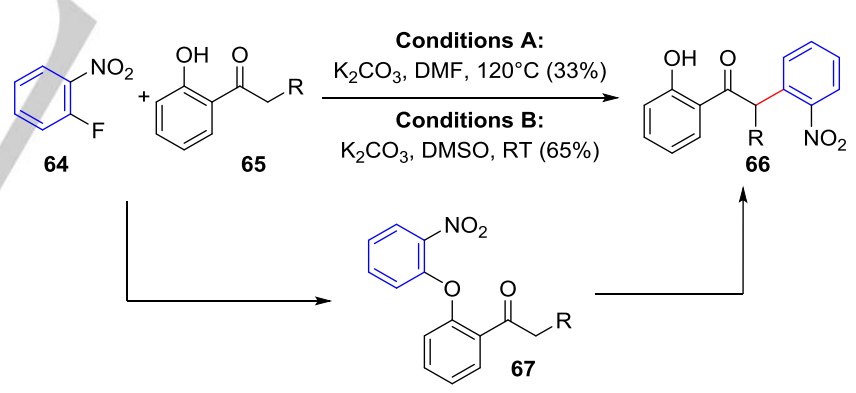

Scheme 19. a-Arylation of aryl ketones via an enolate Truce-Smiles rearrangement.

The range of activating groups which could be employed for this rearrangement was expanded upon by $\mathrm{Ma}$ and $\mathrm{Ma}$ to include heteroarenes, nitriles, trifluoromethyl, and halogen functionality under similarly mild conditions (Scheme 20). ${ }^{[33]}$ 


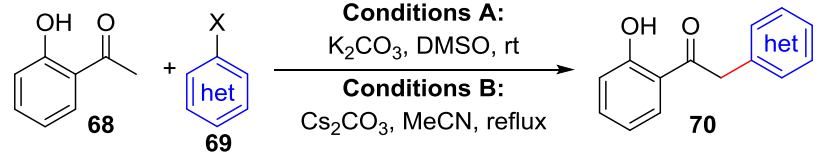

$$
\text { (1) }
$$

Scheme 20. The cascade $S_{N} A r$, Truce-Smiles rearrangement to prepare $\alpha$ arylated ketones.

Snape reported preliminary results in the development of an asymmetric $\alpha$-arylation, which exploited an amide chiral auxiliary 71. However, only low levels of diastereoselectivity (1:1.6) were obtained (Scheme 21). ${ }^{[34]}$ The propensity for racemization at the chiral center in question under the reaction conditions indicated that this may be a consequence of thermodynamic equilibration in the product.

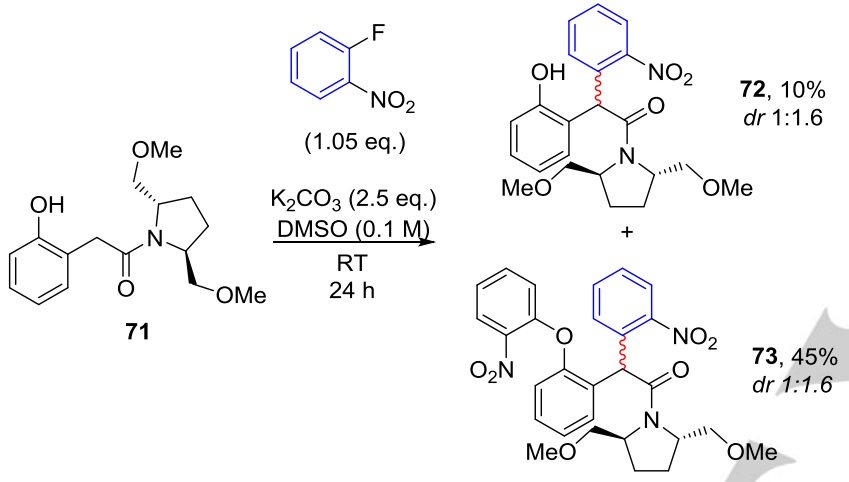

Scheme 21. Diastereoselective Truce-Smiles rearrangement.

\subsubsection{Phenyl ether/nitrile rearrangements}

A series of reports describing the Smiles rearrangement of phenyl ethers, promoted by deprotonation of an alkyl nitrile substrate 74 (Scheme 22) were made by Okuda and Sasaki. ${ }^{[35]}$ These reactions culminate in cyclization and aromatization to afford polycyclic heteroaromatic products. The migration of nonaromatic systems (activated alkenes 76) can be achieved with $\mathrm{NaH} / \mathrm{DME}$, albeit in moderate yields. ${ }^{[35 \mathrm{~b}]}$

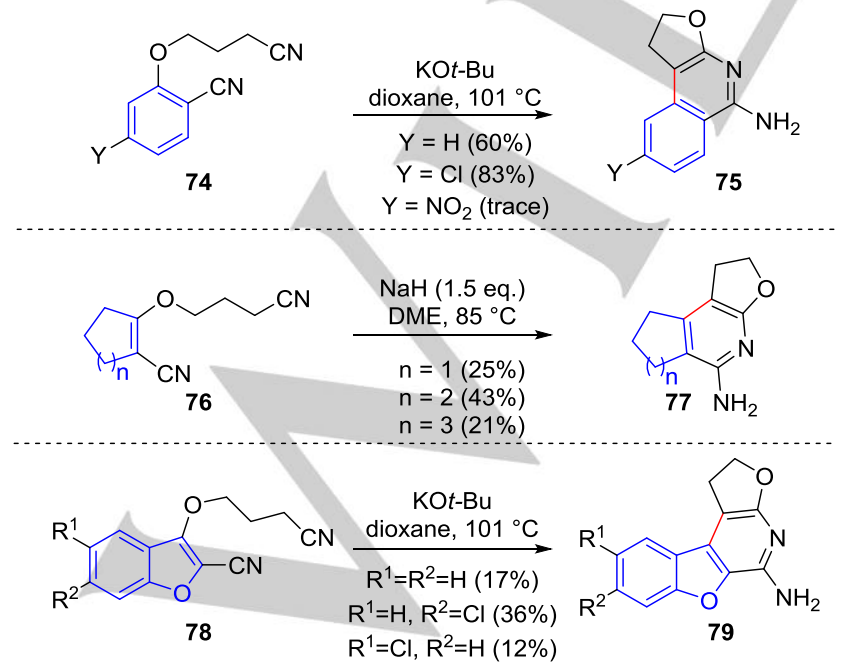

Scheme 22. Deprotonation/rearrangement/condensation cascade of nitrile phenyl ethers.
The rearrangement of phenyl ethers promoted by $\alpha$-nitrile deprotonation was expanded through the development of milder reaction conditions (Scheme 23) by Wood. ${ }^{[36]}$ The rearrangement could be conducted at lower temperatures (up to $60{ }^{\circ} \mathrm{C}$ ) using various electron withdrawing groups on the aryl ring (nitroso, nitrile, ketone, halogens).<smiles>N#CCCCOc1ccccc1</smiles>

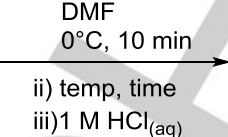

Selected examples

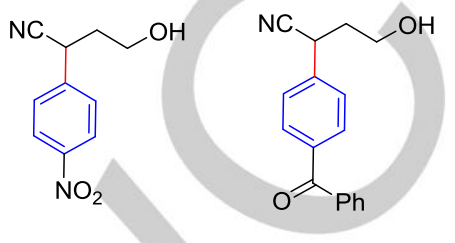

$86 \%\left(20^{\circ} \mathrm{C}, 4 \mathrm{~h}\right)$

$70 \%\left(40^{\circ} \mathrm{C}, 20 \mathrm{~h}\right)$ i) $\mathrm{NaH}(1.5$ eq.)<smiles>N#CC(C=CO)c1ccccc1</smiles>

Scheme 23. Phenyl ether to a-nitrile aryl migration.<smiles>N#Cc1ccccc1C(C#N)CCO</smiles>

$44 \%,\left(20^{\circ} \mathrm{C}, 20 \mathrm{~h}\right)$ $\mathrm{NaH}$ at $20^{\circ} \mathrm{C}$

\subsubsection{Biaryl preparation}

Truce-Smiles rearrangements of aryl anion equivalents to form biaryls are quite rare in the literature. ${ }^{[37]}$ An elegant example was recently reported by Quayle, who observed Truce-Smiles rearrangement during their preparation of potential benzyne precursors 82 (Scheme 24). ${ }^{[38]}$ The TBAF mediated de-silylation of nitrobenzene sulfonate esters resulted in a desulfonative rearrangement of the aryl anion equivalent to afford biaryl phenols 83 .
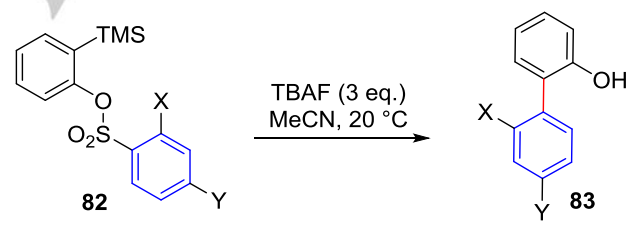<smiles>O=[N+]([O-])c1ccc(-c2ccccc2O)cc1</smiles>

$44 \%$<smiles>O=[N+]([O-])c1ccccc1-c1ccccc1O</smiles>

$39 \%$<smiles>O=[N+]([O-])c1ccc(-c2ccccc2O)c([N+](=O)[O-])c1</smiles>

$49 \%$

Scheme 24. Quayle's desulfonative biaryl nitro-phenol synthesis. One or both of $X$ and $Y$ is a nitro group.

Greaney developed a benzyne-mediated desulfonative Truce- Smiles reaction for the synthesis of 2-aminobiaryls from phenylsulfonamides 84 (Scheme 25). ${ }^{[39]} \mathrm{N}$-Arylation of electron poor sulfonamides with benzyne generates an incipient ary anion that can rearrange to the biaryls 85 . Several electronwithdrawing functionalities were productive in activating the migrating arene, in addition to heteroaromatic ring systems. Further, highly hindered biaryls including those displaying axial chirality (e.g. 86) were readily prepared. As with the Quayle system, this transformation creates the biaryl C-C bond with no requirement for expensive Noble metal catalysts or organometallic intermediates. 
<smiles>[R]NS(=O)(=O)c1ccc(C([R])([Na])O[Na])cc1</smiles>

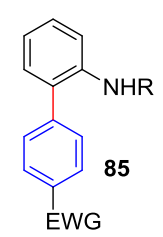

85
Selected examples

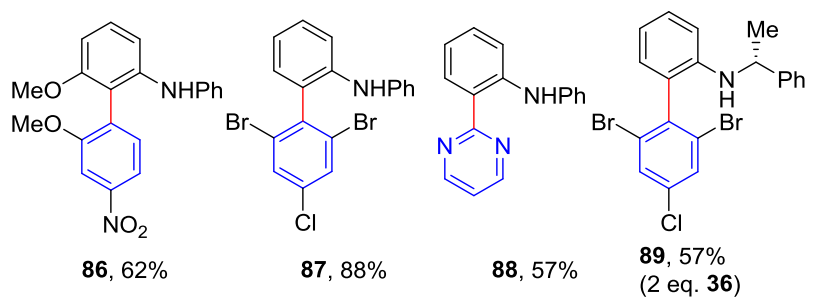

Scheme 25. An aryne mediated Truce-Smiles biaryl synthesis.

\subsubsection{Sulfonamide/enolate rearrangement}

The rearrangement of nosyl protected amino acids $\mathbf{9 0}$ was observed in 1999 by Wilson and co-workers (Scheme 26). ${ }^{[40]}$ The rearrangement proceeded rapidly at ambient temperature with $50 \% \mathrm{Bu}_{4} \mathrm{NOH}$ in dioxane. Several non-polar amino acids were shown to be susceptible to rearrangement to afford the $\alpha$ arylated quaternary center-containing amino acid esters 91. Para-nitrobenzene sulfonamides were more reactive than the corresponding ortho-nitrobenzene sulfonamides.
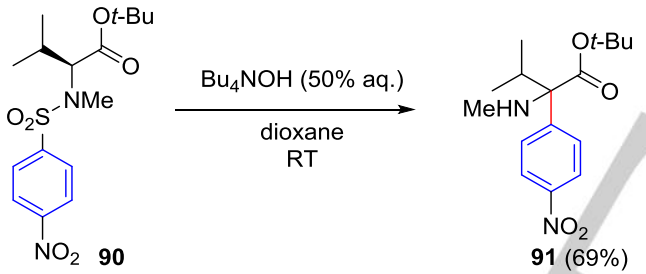

Scheme 26. The first sulfonamide enolate aryl migration.

This transformation was expanded upon by Penso and Lupi through in situ alkylation and deprotonation of Fukuyama sulfonamides $92,{ }^{[41]}$ which lead to desulfonative rearrangement to afford $\alpha$-quaternary amino acid derivatives (Scheme 27). ${ }^{[42]}$ Enantiomerically-pure starting materials were, under certain conditions, converted to products 93 in moderate to good enantiomeric excess. The mechanism for this retention of chirality was proposed to be through "memory of chirality" leading to a non-symmetric enolate intermediate. Doping the reaction with a non-alkylated chiral sulfonamide additive enhanced the retention of chirality, with this ester being recovered with $100 \%$ ee. Phenyl glycine was recovered with particularly poor ee, due to the faster rate of racemization of these substrates.

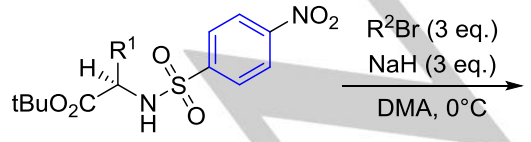

92 (single enatiomer)

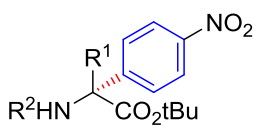

$93(58-98 \%$ ee)
Scheme 27. $\mathrm{N}$-alkylation/aryl migration to afford $\alpha$-aryl amino acids.

This work was extended to the enantioselective rearrangement of proline sulfonamides 94 (Scheme 28), ${ }^{[4]}$ where highly enantioenriched $\alpha$-arylated rearrangement products 95 were isolated. A memory of chirality mechanism was also invoked here with the high enantioselectivity compared to the non-cyclic enolates rationalized by the greater rigidity of the system. The optimal conditions used $\mathrm{NaH}$ with ammonia gas; it was proposed that ammonia abstracts the sodium ion from the intermediate enolate enabling the formation of a loose ion pair which is more reactive than the unsolvated sodium enolate tight ion pair. Strongly electron withdrawing groups were required (nitro or nitrile), although 2,4-dinitrobenzene gave only a mixture of byproducts. In addition, sterically hindered substrates were not viable under the reaction conditions.

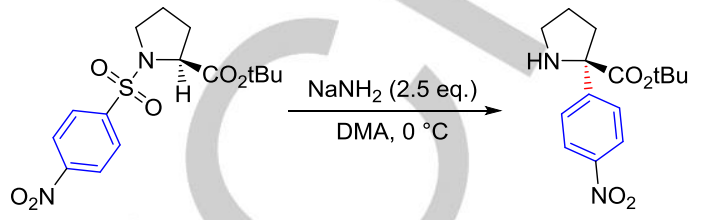

94 (single enantiomer)

95 (91 to $96 \%$ ee)

Scheme 28. Enantioselective arylation of prolines via a Truce-Smiles rearrangement.

A desulfonative intramolecular arylation of amino acid derivatives 96 was developed for the synthesis of a library of advanced intermediates for heterocycle synthesis by Krchňák (Scheme 29). ${ }^{[4]}$ The regioselectivity of aryl ring migration depended upon both the substitution pattern and the amino acid carboxyl-terminal functionality. A free $\mathrm{N}-\mathrm{H}(\mathrm{X}=\mathrm{NH})$ facilitates a dual Smiles rearrangement to afford $\mathrm{N}$-arylated products 98 . For substrates with no free $\mathrm{N}-\mathrm{H}\left(\mathrm{X}=\mathrm{O}, \mathrm{NR}^{4}\right)$, regioselectivity depends upon the electronics of the $N$-benzyl group $\left(\mathrm{R}^{1}\right)$, with arylation occurring at either the benzylic $\mathbf{9 7}$ or a-carbonyl carbon 99. The reactions were conducted on a solid support resin in the presence of DBU in DMF at ambient temperature for 16 hours. The a-arylation of amino acid derivatives from alcohols and nitrobenzene sulfonyl chlorides was then described for a large library of compounds. ${ }^{[44 a]}$ The reactions were all observed to proceed with epimerization of the quaternary center.

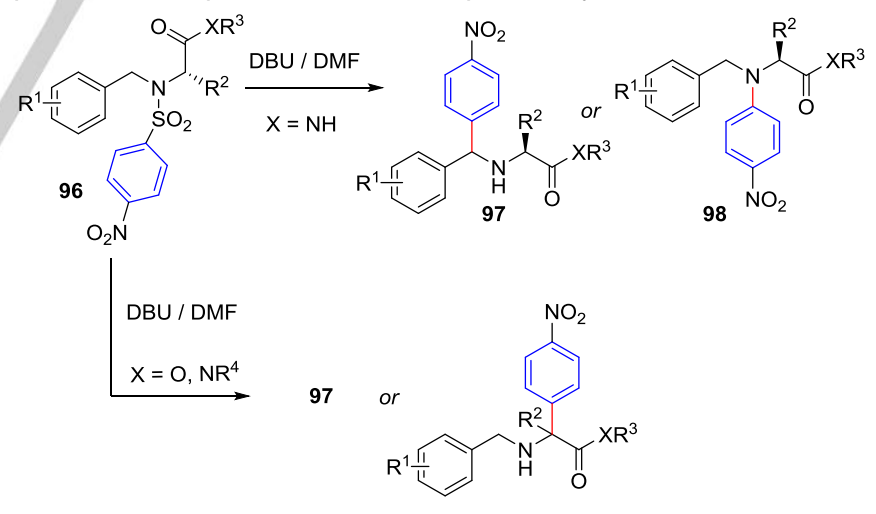

99

Scheme 29. Desulfonative aryl migration of amino-acid derivatives for the combinatorial preparation of heterocycles.

A $\operatorname{Pd}(\mathrm{II})$ catalyzed cascade reaction, in which an alkyl bromide is coupled with $\mathrm{N}$-sulfonylated acrylamides 100 , was reported by $\mathrm{Li}$ (Scheme 30). ${ }^{[45]}$ The reaction was envisaged to proceed through a Heck-type mechanism where the initial alkene carbopalladation product undergoes ipso-cyclization to form the dearomatized spirocyclic palladium intermediate, followed by desulfonation and re-aromatization. The transformation is related to the copper-catalyzed radical Truce-Smiles transformations reported by Nevado and others (vide infra). Here also, electron rich arenes migrated with a better yield than the electron deficient arenes. The differing reactivity of $\mathrm{N}$-aryl 
and $\mathrm{N}$-alkyl substrates is also consistent with that of the radical regime, whereby $\mathrm{N}$-alkyl substrates undergo subsequent $\mathrm{N}$ arylation to afford oxindoles 102.

$$
\text { 28 examples (trace - 92\%) }
$$
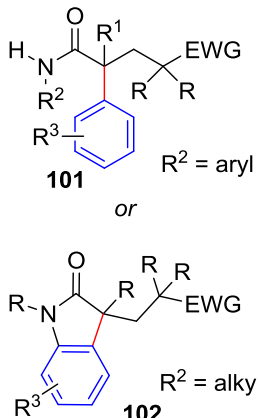

Scheme 30. Oxidative Heck/desulfonative Truce-Smiles rearrangement.

Canesi recently demonstrated the use of nosyl groups in several intramolecular Michael addition / Truce-Smiles rearrangement reactions. ${ }^{[46]}$ Intramolecular addition of the nosyl-amine in $\mathbf{1 0 3}$ to the enone led to Truce-Smiles rearrangement, however, the final product 104 was a result of a retro-Michael and second 1,4addition of the amine (Scheme 31, a). This concept was also demonstrated with the addition of sulfones to enones and dienamines under the same reaction conditions. Finally, if the sulfonyl moiety was incorporated into the dienamine 105, a Michael addition of dimethylmalonate (Scheme 31, b) could trigger the Truce-Smiles rearrangement.

(a)

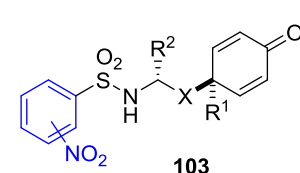

$\mathrm{X}=\mathrm{CH}_{2}, \mathrm{OCH}_{2}$

$\mathrm{R}_{1}=\mathrm{OMe}, \mathrm{OEt}, \mathrm{NHAc}, \mathrm{Et}$ $\mathrm{R}_{2}=\mathrm{H}, \mathrm{CO}_{2} \mathrm{Me}, \mathrm{Me}$
$\mathrm{NO}_{2} \quad 103$

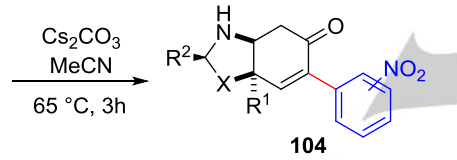

11 examples $(63-94 \%)$ (b)<smiles>COC1(OC)C=C/C(=N\[S-](=O)(O)c2ccccc2[N+](=O)[O-])c2ccccc21</smiles>

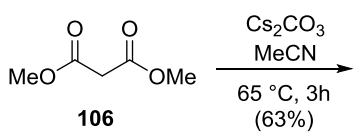

$(63 \%)$

105

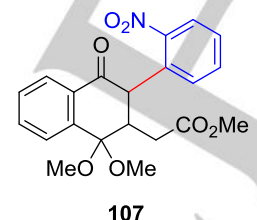

107
Scheme 31. Tandem Michael addition / Truce-Smiles reactions

\subsubsection{Aryl amide/enolate rearrangement}

Kündig observed an unexpected rearrangement of aryl amides 108 during the investigation of parallel transition-metal catalyzed processes (Scheme 32). ${ }^{[4]}$ This rearrangement proceeds via a 4-membered spirocycle 110 and DFT calculations indicated that the unobserved substitution step was no more energetically disfavored than the observed rearrangement. Rather, that the differences in energy were very small and reaction progress was likely easily effected by substitution pattern. The reaction gave good to excellent yields for halogenated aza-heterocycles. A pyridyne intermediate, via an elimination pathway, was ruled out through deuterium labelling experiments.

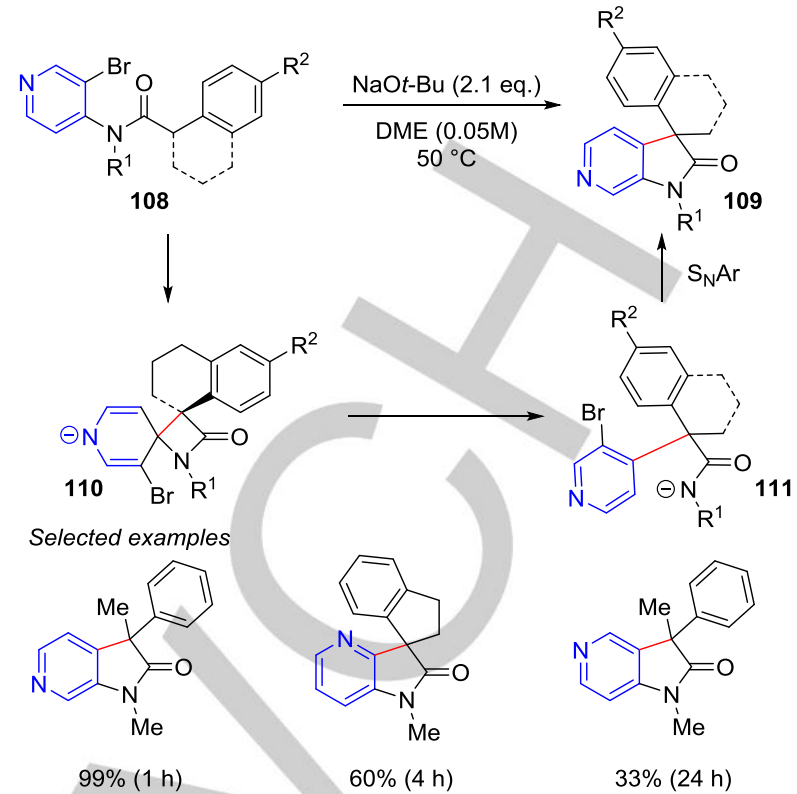

Scheme 32. A Truce-Smiles rearrangement via a four membered spirocycle, followed by cyclization.

Al-awar reported another amide enolate Truce-Smiles rearrangement also via a four membered transition state, but under mildly basic conditions (Scheme 33 ).$^{[48]}$ However, only 3substituted pyridines 112 were viable substrates, and substitution at the 2-position lead solely to the $\mathrm{N}$-acylated products. Notably, the rearrangement of a nitro-phenyl analogue did not occur under these reaction conditions, and so it was proposed that activation of the pyridine occurred through acylation or protonation of the pyridine nitrogen.

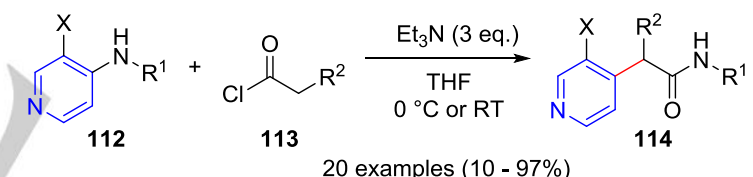

Scheme 33. An electrophile-activation promoted Truce-Smiles rearrangement.

\subsubsection{Clayden Rearrangement}

Whilst investigating the lithiation of $\mathrm{N}$-benzyl ureas, Clayden and co-workers discovered an unprecedented intramolecular aryl migration, which has subsequently developed into a rich area of chemistry for lithiated ureas, carbamates and thiocarbamates (Scheme 34). ${ }^{[4]}$ Upon lithiation of 115 (either through direct lithiation or nucleophilic addition of an organolithium to an unsaturated $\mathrm{C}-\mathrm{C}$ bond), a 1,5-aryl shift takes place to give the secondary benzylic derivative 116. The migration of the distal aryl group can proceed stereospecifically, although with different senses of stereochemistry depending upon the type of substrate. Stereoselective lithiation, therefore, results in the synthesis of enantio-enriched tertiary amines, alcohols, and thiols upon hydrolytic cleavage of the carbonyl moiety. 


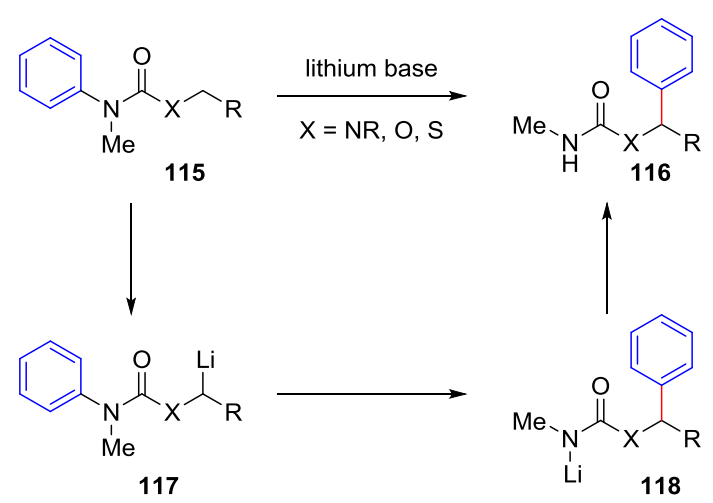

Scheme 34. Lithiation/aryl migration of ureas and (thio)carbamates.

\subsubsection{Deprotonation promoted Clayden rearrangement}

\subsection{Ureas}

The first nitrogen to carbon aryl migration was observed during the investigation of the regiospecific lithiation of ureas 119 (Scheme 35). ${ }^{[50]}$ Both lithiated benzyl and alkenyl ureas underwent rearrangement to give aminodiaryl-methanes and aminoarylalkyl-methane products $\mathbf{1 2 0}$. The migration was shown to be stereospecific and proceed with retention at the carbon center. However, re-protonation of lithiated $\mathbf{1 1 9}$ was unselective and overall stereoselectivity depended upon the reaction solvent. In some cases, the spirocyclic intermediate could be isolated through oxidation or methylation giving evidence for a Smiles-type rearrangement. However, in contrast to the requirement for highly electron poor aryl groups for classical Smiles rearrangements, electron rich and neutral substrates gave the best yields. Subsequently, $\alpha$-pyridylation of chiral amines was also reported using this method. ${ }^{[51]}$ The reaction was also applied to cyclic amines; secondary amines (tetrahydroisoquinoline) readily underwent aryl migration under standard conditions whereas addition of DMPU was required to affect benzylic lithiation for the more hindered tertiary amines. ${ }^{[52]}$

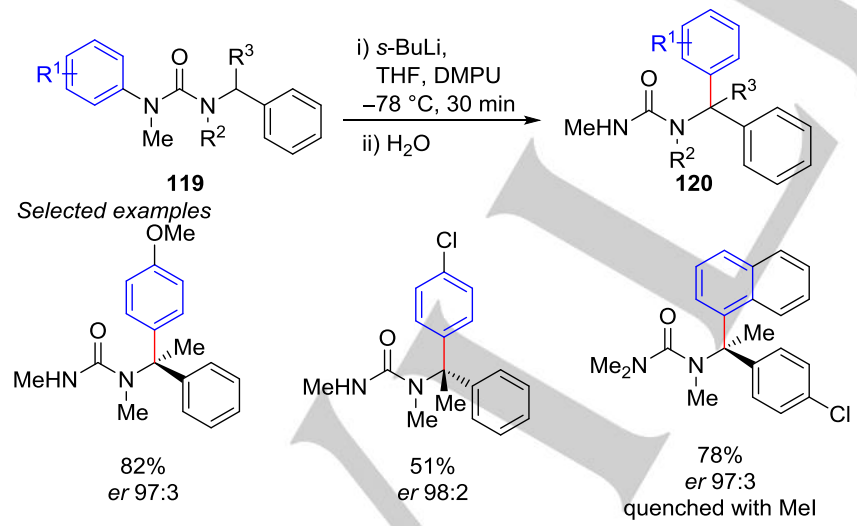

Scheme 35. A lithiation induced stereospecific nitrogen to carbon aryl transfer of ureas.

A deprotonation, rearrangement cascade sequence was demonstrated with $\mathrm{N}$-allyl ureas 121 (Scheme 36). ${ }^{[53]}$ Initial Clayden rearrangement of 121 gave 122, with the double bond moving into conjugation after a second lithiation/protonation. Palladium catalyzed $\mathrm{N}$-arylation formed urea 123 , which underwent stereoselective deprotonation with a chiral lithium amine, then a second nitrogen to carbon aryl migration to give diaryl allyl amines 124 with excellent er. The stereochemical outcome of the reaction was proposed to be a result of the enantioselective formation of a configurationally stable planar chiral allyl lithium and stereospecific rearrangement, as opposed to stereoselective reaction of a configurationally labile allyl lithium species. In principle, these diarylallylamine ureas could be oxidized to provide access to amino acid derivatives. The rearrangement of $\mathrm{N}$-allyl ureas was also reported for the multigram synthesis of 1-arylcycloalkenamines. ${ }^{[54]}$

$$
\begin{aligned}
& \text { ii) } \mathrm{DMPU},-78^{\circ} \mathrm{C}, 3 \mathrm{~h} \\
& \text { iii) } \mathrm{MeOH}
\end{aligned}
$$

Scheme 36. Sequential double arylation of $\mathrm{N}$-allyl ureas.

The Clayden rearrangement suggests a direct route to $\alpha$ arylated non-natural amino acids using amino acid-derived ureas 125. However, the direct transformation of ureas to these valuable products was complicated by hydantoin (126) formation following aryl migration of amino acid enolates (Scheme 37). ${ }^{[55}$ Fortunately, upon oxidation of the N-PMB protecting group and hydrolysis, the desired amino acid derivatives could be revealed. Extensive mechanistic investigations were conducted using in situ IR spectroscopy, however no direct evidence for a nonaromatic spirocyclic intermediate could be acquired, despite the observation of several lithiated intermediates.

$$
\begin{array}{ll}
\text { ii) } 1 \mathrm{M} \mathrm{HCl} \\
24 \text { examples }(52-99 \%)
\end{array}
$$
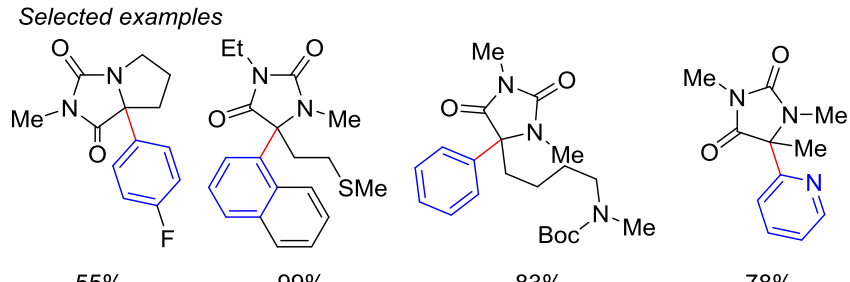

Scheme 37. Aryl migration and cyclization to form hydantoins.

An asymmetric $\alpha$-arylation of amino acid derivatives 127 using the rearrangement was developed by Kawabata (Scheme 38). ${ }^{[56]}$ As with the Truce-Smiles rearrangement of nitrobenzene sulfonamide protected amino acids reported by Lupi and Penso ${ }^{[42]}$ (vide supra) this approach involved a memory of chirality mechanism. The axially chiral enolate intermediate $\mathbf{1 2 9}$ has a limited half-life, and so the reaction of the enolate with an electrophile can compete with racemization of the chiral enolates. The migration of the arene proceeds with inversion and the final product is also a hydantoin 128. Typical conditions used LiHMDS, as KHMDS typically improved the yield, but decreased the enantioselectivity of the reaction. The solvent, time and temperature were optimized for some substrates 
(including warming to ambient temperature over 12 hours). The 4- $\mathrm{MeOC}_{6} \mathrm{H}_{5}$ substrate did not rearrange, and so was used to determine a barrier to racemization of the intermediate enolate of $15.2 \mathrm{kcal} / \mathrm{mol}$ at $-78{ }^{\circ} \mathrm{C}$, leading to an estimated value of halflife to racemization of 5 minutes.

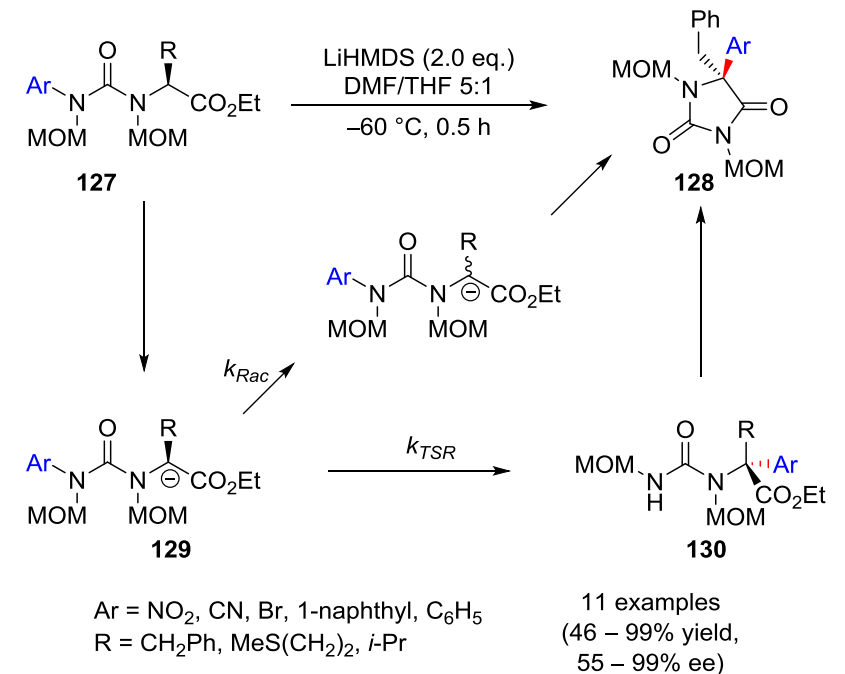

Scheme 38. Asymmetric $\alpha$-arylation of amino acid derivatives using memory of chirality.

The use of a pseudoephedrine chiral auxiliary was also shown to enable enantioselective $\alpha$-arylation of amino acid derivatives by Clayden and co-workers (Scheme 39). ${ }^{[57]}$ The rearrangement of 131 leads to the formation of hydantoin $\mathbf{1 3 2}$ through cyclization and expulsion of the pseudoephedrine auxiliary, which could be readily recovered. Initial investigations of strong bases gave very poor er in the hydantoin product. The addition of $\mathrm{LiCl}$, however, whilst employing LDA as a base, lead to a reasonable e.r. at small scale. The coordination environment of the nitrogen was hypothesized to cause the erosion of enantioselectivity. Optimal conditions were determined following extensive investigations into the use of both $\mathrm{LiCl}$ and $\mathrm{TMSCl}$ additives. These conditions were complex (Scheme ) but provided the hydantoin in 98:2 er, however in the opposite sense to when just a $\mathrm{LiCl}$ additive as used. The conditions could be applied to a variety of amino acids, furthermore, nitrogen and sulfur containing amino acids could tolerate the reaction conditions. Various electron rich, neutral, and poor aromatics were shown to migrate, including heteroaromatic substrates. The hydantoins could then be converted to the quaternary amino acids using basic hydrolysis (4 $\mathrm{M} \mathrm{NaOH}$, heat).

The direct lithiation Clayden rearrangement has also been applied to proline derivatives, ${ }^{[58]}$ piperidines, ${ }^{[59]}$ and pyrrolines. ${ }^{[59]}$

\subsection{Carbamates and thiocarbamates}

Lithiation promoted aryl migrations have also developed for carbamates 133 (Scheme 40). ${ }^{[6]}$ The diaryl methanol carbamate products 134 were not configurationally stable under the reaction conditions and so erosion of enantiomeric enrichment was initially observed, but the exclusion of coordinating solvents such

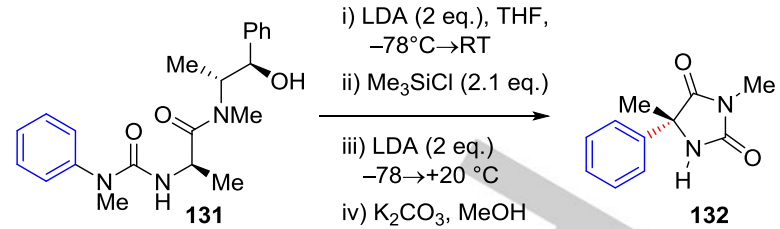

Selected examples<smiles>CN1C(=O)N(C)[C@@](C)(c2ccccc2)C1=O</smiles>

$83 \% 92: 8$<smiles>CN1C(=O)N[C@@](C)(c2cccc(F)c2)C1=O</smiles>

$45 \% 55: 45$

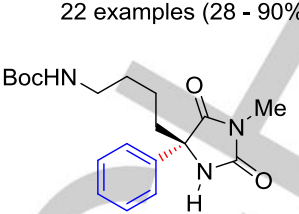

$57 \% 92: 8$

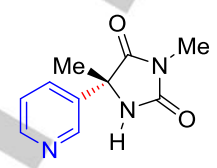

$50 \% 85: 15$ as THF and DMPU enabled the reaction to proceed with greater enantioselectivity. The method was used to prepare $(S, S)$ clemastine through an invertive nitrogen to carbon aryl migration (cf the rearrangement of ureas, which proceed with retention). ${ }^{[61]}$
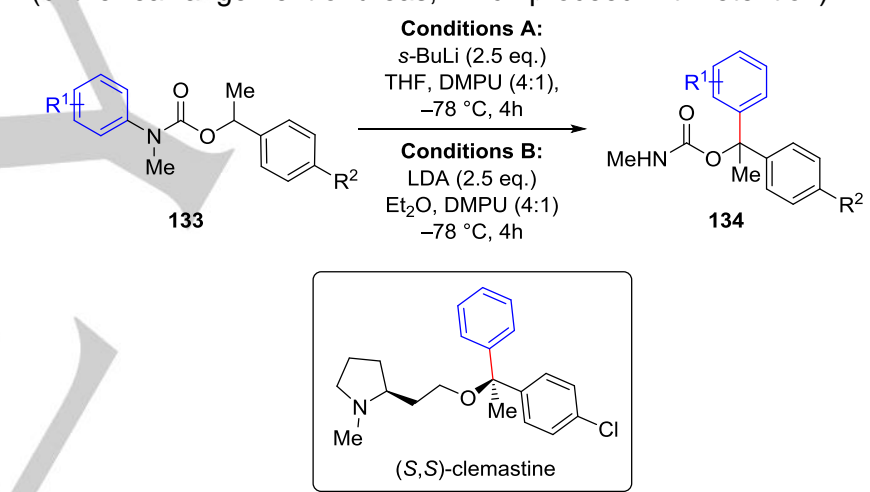

Scheme 40. Carbamate aryl migration and $(S, S)$-clemastine synthesis.

Aryl migration from nitrogen to carbon was also reported for thiocarbamates 135 (Scheme 41). ${ }^{[62]}$ Lithiation at the benzylic position promoted aryl migration, the products of which could be hydrolyzed with sodium ethoxide to reveal secondary and tertiary thiols. In contrast to most urea and carbamate rearrangements, electron-deficient substituents gave a greater yield. The migration was determined to proceed with retention at the carbanion center in the case of a-substituted substrates. High fidelity of the chiral information was attributed to the stability of $S$-benzylic thiocarbamates up to $0^{\circ} \mathrm{C}$. The loss of enantiomeric enrichment was observed to be time dependent and thus was proposed to be due to partial racemization of the benzyl lithium intermediated rather than incomplete retentive migration. The transformation has also been extended to $S$ allylic thiocarbamates with similar results. ${ }^{[63]}$

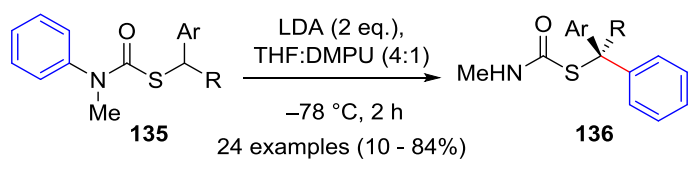

Scheme 41. Thiocarbamate aryl migration. 


\subsubsection{Clayden rearrangement promoted by nucleophilic addition}

The nucleophilic addition of an organolithium to vinyl ureas, carbamates and thiocarbamates is also observed to promote nitrogen to carbon aryl migration, affording tertiary alcohol, amine, and thiol products upon hydrolysis.

The tandem $\beta$-alkylation- $\alpha$-arylation of vinyl ureas 137 was the first example of the formation of two carbon-carbon bonds using the aryl migration of ureas (Scheme 42) ${ }^{[64]}$ Carbolithiation with various alkyl-, alkenyl and aryl-lithiums gave rearrangement to product 138, with an overall syn addition to (Z)- and (E)alkenes.

$$
\begin{aligned}
& \mathrm{Ar}_{-}^{2} \mathrm{~N}_{1}^{\mathrm{O}} \mathrm{N}_{\mathrm{N}}^{\mathrm{Ar}} \mathrm{Ar}^{1} \\
& \mathrm{Me} \mathrm{Me} \\
& 137
\end{aligned}
$$

$$
\begin{aligned}
& \underset{\text { i) } \mathrm{RLi} \text {, solvent, temp. }}{\stackrel{\text { ii) } \mathrm{MeOH}}{27 \text { examples (54 - 96\%) }}} \\
& \text {. }
\end{aligned}
$$

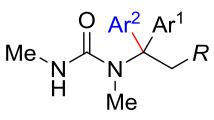

$$
\begin{aligned}
& 138
\end{aligned}
$$

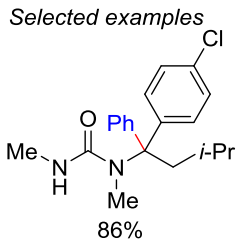<smiles>CCC(c1ccccc1)(c1ccccc1)N(C)C(=O)NC</smiles>

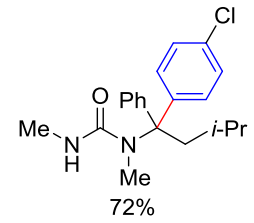
(THF, $\left.-50{ }^{\circ} \mathrm{C}, 90 \mathrm{~min}\right)$ (THF, $-50^{\circ} \mathrm{C}, 90 \mathrm{~min}$ )

$$
\text { (THF, }-50^{\circ} \mathrm{C}, 90 \mathrm{~min} \text { ) }
$$<smiles>CN(C(=O)N[N+](C)=O)[C@H](c1ccc(F)cc1)C(C)(C)C(C)(C)C</smiles>

from $(E)-13796 \%$ (THF, $\left.-40{ }^{\circ} \mathrm{C}, 3-6 \mathrm{~h}\right)$<smiles>COc1ccc(C(N(C)C(=O)NC(C)(C)C)C(C)(C)C(F)(F)F)cc1</smiles>

From $(E)-13760 \%$ $\left(\mathrm{PhMe},-40^{\circ} \mathrm{C}, 1 \mathrm{~h}\right.$ then DMPU, $-40 \rightarrow R T, 16 \mathrm{~h}$ )

Scheme 42. Carbolithiation-migration of vinyl ureas.

An enantioselective carbolithiation / aryl migration was developed ${ }^{[65]}$ using (-)sparteine or a (+)sparteine surrogate to prepare enantiomerically-enriched benzyl lithium species. The addition of DMPU to these lithiated intermediates caused nitrogen to carbon aryl migration to afford enantioenriched benzylic tertiary amine derivatives, which could be hydrolyzed to the chiral tertiary alkyl amines. The reaction was successfully extended to carbamates and thiocarbamates, although enantioselective rearrangement was more challenging for these substrates. ${ }^{[66],[67],[68]}$

\subsubsection{Mechanism}

The facility of electron rich arenes to migrate with higher yields than electron deficient arenes in some examples of the Clayden rearrangement is unusual in Smiles chemistry, although not unprecedented with respect to some Truce-Smiles processes (cf Scheme 2). ${ }^{[6]}$ The mechanistic underpinnings have been studied in some depth by the Clayden group, with one explanation proposed being the identification of a reverse Truce-Smiles rearrangement - electron deficient arenes can undergo the reverse carbon to nitrogen migration with weaker bases (Scheme 43). ${ }^{[69]}$ Furthermore, only catalytic quantities of the base were required to promote the reverse migration. The electron rich aryls were unable to migrate, and competition reactions identified the most electron deficient ring as migrating preferentially. The carbon-to-nitrogen migration was only observed in the presence of lithium cations, whilst the reverse migration could take place in the presence of both metallic and non-metal counter-cations (DMU, TBAF). As in the nitrogen to carbon migration, no transient dearomatized spirocyclic intermediates were detected.

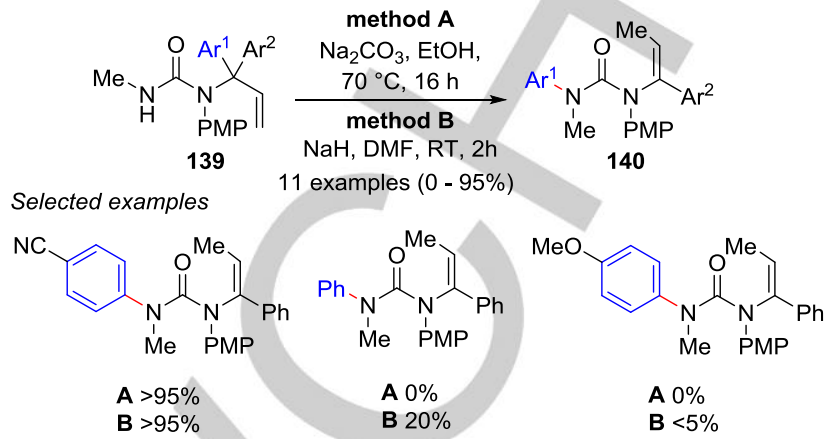

Scheme 43. A reverse Truce-Smiles aryl migration of ureas.

Excellent evidence for a spiro-cyclic Meisenheimer intermediate was described in the initial disclosure, where a dearomatized species was obtained by exposing the reaction of 141 to dry air (Scheme 44). ${ }^{[50]}$ X-ray crystallography confirmed the absolute stereochemistry of this product and provided evidence for a retentive rearrangement.
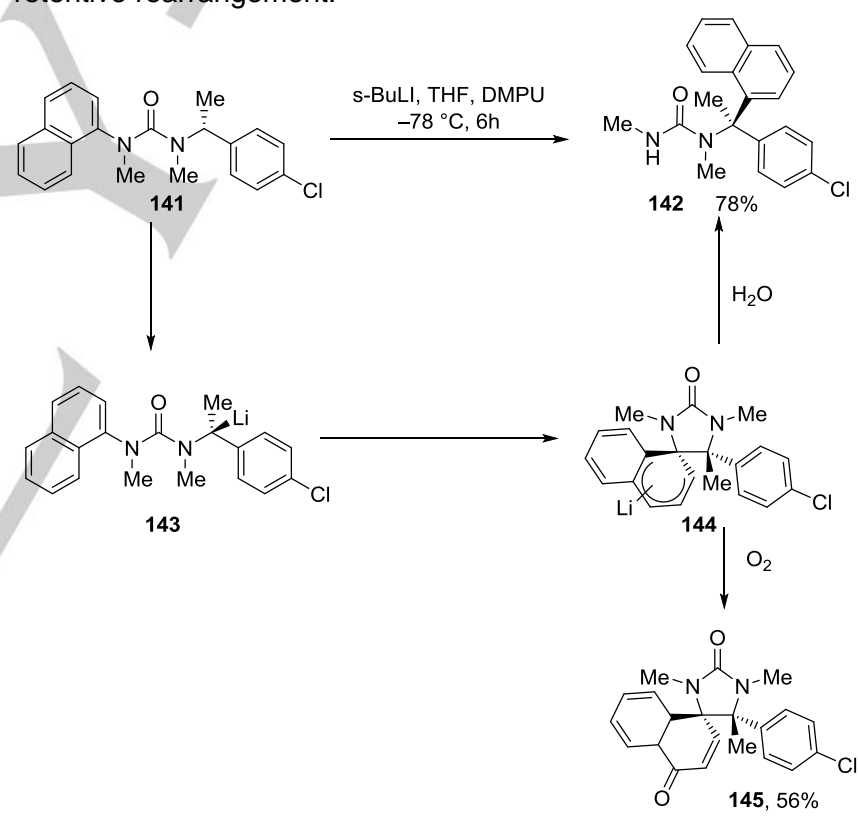

Scheme 44. Oxidation of the Meisenheimer intermediate to afford a spirocyclic enone.

The potential dearomatized intermediate which is formed during the arene migration has not, however, been detected though insitu IR experiments or NMR spectroscopy, nor located using DFT calculations. ${ }^{[70,[71],[72]}$ The naphthyl substrate is an exception, as a significantly de-shielded proton ( $\delta$ 9.4) was observed whilst monitoring the reaction by ${ }^{1} \mathrm{H}$ NMR spectroscopy, and assigned to 144. DFT calculations also located a short-lived spiro-cyclic intermediate which collapsed to eliminate a lithiated urea. The migration of the solvated lithium cation from the benzylic anionic center to a site close to the adjacent phenyl ring allows attack of the benzylic anion on the more remote aromatic ring. This occurs with the concomitant migration of the solvated lithium cation which stabilizes the 
migrating negative charge.

\section{Single Electron Smiles Rearrangement}

Although Smiles rearrangement reactions are classically two electron processes, many one electron processes have also been developed in recent years. This area has been recently reviewed $;^{[5 a, 5 b]}$ here we focus on a representative selection of radical Smiles rearrangements from the current literature that offer a complimentary approach to the polar transformations described in section 2 .

\section{1 $C-X$ bond formation}

Smiles migration of an arene to a heteroatom, with C-C bond cleavage, is uncommon. Shi reported an example involving the formation of a nitrogen centered radical, generated from the triflamide 146 through oxidation with catalytic $\mathrm{AgOAc}$ and stoichiometric $\mathrm{Phl}\left(\mathrm{OCOCF}_{3}\right)_{2}$. This triggers aryl transfer from carbon to nitrogen leading to the formation of a stabilized benzylic radical which is further oxidized to the benzylic cation and quenched with the TFAO anion (Scheme 45). ${ }^{[73]}$ The most electron rich arene is transferred preferentially.

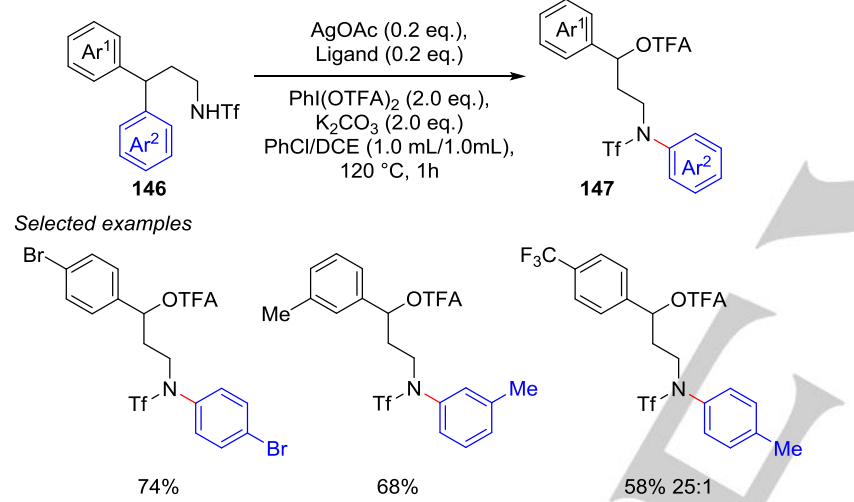

Scheme 45. A long distance carbon to nitrogen radical aryl migration.

\subsection{C-C Radical Truce-Smiles reactions}

Most radical Smiles rearrangements result in carbon-carbon bond formation. Electron withdrawing arene functionality is not required for arene migration, which can be initiated through many radical forming processes. As with the polar Truce-Smiles reaction (sections 2.2.1.3 and 2.2.1.4), the use of aryl sulfonamide derivatives is a powerful method for aryl transfer through the extrusion of $\mathrm{SO}_{2}$. This drives the reaction, prevents the reverse migration, and enables cascade processes to be designed which access less stable radical species as intermediates.

Formative work in this area came from Speckamp ${ }^{[74]}$ and Motherwell, ${ }^{[75]}$ who demonstrated radical Smiles type rearrangement in the synthesis of biaryl derivatives. Recent work from Sapi and co-workers incorporated this chemistry into a cascade reaction for the synthesis of oxindoles 149 (Scheme 46). ${ }^{[76]}$ Some side reactions were observed, including the addition of the amidyl radical to the newly formed indole to afford dearomatized products.

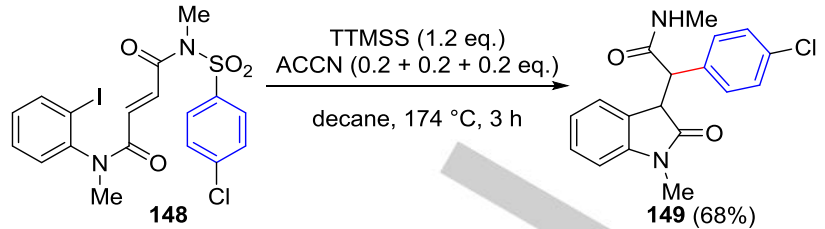

Scheme 46. A radical cascade process involving a Truce-Smiles rearrangement. TTMSS: tris(trimethylsilyl)silane; ACCN 2,2'azocyclohexanecarbonitrile.

Nevado and co-workers have developed a highly versatile aryl migration/desulfonation cascade based upon copper catalyzed 1,4-addition of, initially, a trifluoromethyl radical to an $\alpha, \beta$ unsaturated amide $150 .{ }^{[77]}$ The resultant radical 151 can then undergo Smiles rearrangement, with the fate of the product amidyl radical 152 dependent on the substitution pattern (aryl, alkyl), with either hydrogen abstraction or cyclization reactions possible. This cascade has been developed to encompass numerous radical sources, and the amidyl radical can be trapped by various intra- and intermolecular electrophiles resulting in a rich variety of multicyclic molecular scaffolds (Scheme 47). ${ }^{[78]}$ Whilst anionic Truce-Smiles rearrangements are principally initiated through deprotonation rather than comparatively rare conjugate-addition, several examples of radical mediated rearrangements, initiated by addition to alkenes and alkynes have now been reported by the Nevado group.

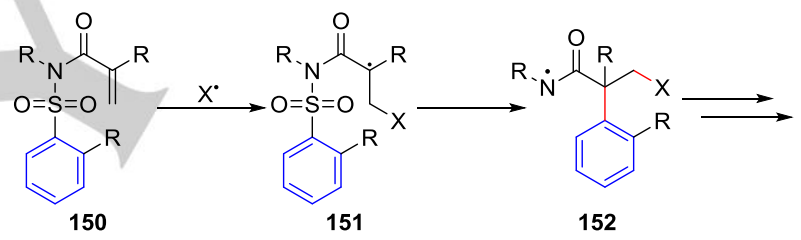

$X=\mathrm{Ar}_{2} \mathrm{P}(\mathrm{O}), \mathrm{N}_{3}, \mathrm{CF}_{3}, \mathrm{SCF}_{3}, \mathrm{CH}(\mathrm{COMe})_{2}, \mathrm{R}_{\mathrm{f}}$,

Example scaffolds<smiles>CC(C)(CSCC(F)(F)F)C1(C)C(=O)n2c(c(-c3ccccc3)c3ccccc32)-c2ccccc21</smiles><smiles>CC(=O)C1=C(C)N(c2ccccc2)C(=O)C(C)(c2ccccc2)C1</smiles><smiles>C[C@]1(C(=O)Nc2ccccc2)C[C@H](CN=[N+]([O-])[O-])c2ccccc2-c2ccccc21</smiles><smiles>Cc1ccc2c(c1)N(C)C(=O)C2(C)CC(F)(F)F</smiles><smiles>CC(CC(F)(F)F)(C(=O)NCCBr)c1ccc(Cl)cc1</smiles>
$60 \%$

Scheme 47. Nevado's generation of amidyl radicals though conjugate addition / Smiles rearrangement.

Zeng et al. reported a copper mediated reaction of alkynes with $N$-fluorosulfonylimide (NFSI) and alcohols to produce valuable $\alpha$ amino- $\alpha$-aryl ketone 154 or $\alpha$-alkyloxyl- $\alpha, \alpha$-diaryl imine products 156 (Scheme 48). ${ }^{[79]}$ These products were formed through a cascade process initiated by the addition of a nitrogen-centered sulfonimidyl radical to an alkyne to form a highly unstable alkenyl radical. An aryl migration and desulfonation (radical Truce-Smiles) followed by oxygenation with alcohols gave an alkyloxyl-a, $\alpha$-diaryl imine (156), whilst a subsequent semipinacol rearrangement afforded the $\alpha$-amino- $\alpha$-aryl ketones 154 upon heating. In the case of unsymmetrical sulfonimides, the more electron rich aromatic was preferentially transferred. 


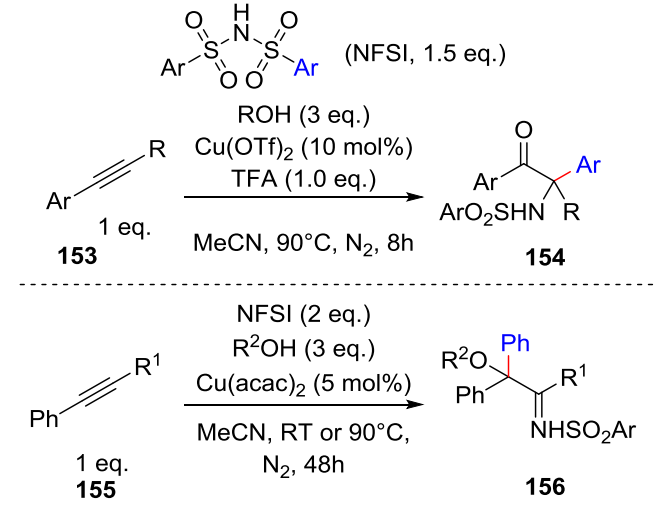

Scheme 48. Alkyne radical cascade involving a Truce-Smiles aryl migration

Shenvi employed a manganese mediated hydrogen atom transfer (HAT) reduction of an alkene 157 in order to initiate aryl transfer in sulfonated menthol derivatives $158,{ }^{[80]}$ which resulted in the formation of all carbon quaternary centers in some cases (Scheme 49).

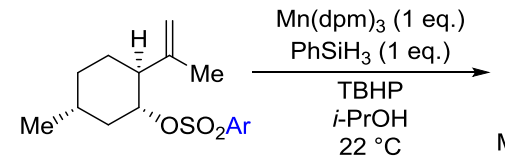

157

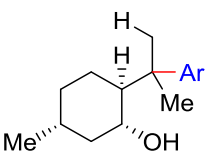

158
Scheme 49. Hydrogen atom transfer-induced Truce-Smiles rearrangement.

Stephenson reported a visible-light-mediated process to initiate radical formation through photoredox-catalyzed homolytic cleavage of the $\mathrm{C}-\mathrm{Br}$ bond in 159 (Scheme 50). ${ }^{[81]}$ Difluoroarylethanol $\mathbf{1 6 0}$ derivatives could thus be prepared from sulfonates of bromodifluoroethanol, which is readily accessed by reduction of bromodifluoroethylacetate. Subsequently, it was found that this reaction proceeded via a radical chain propagation which could be initiated with either a $300 \mathrm{~W}$ white LED or heat. This knowledge enabled the reaction to be conducted on $100 \mathrm{~g}$ scale. ${ }^{[82]}$ The scope of aryls which can be transferred in this process is much broader than many of the corresponding two electron processes.

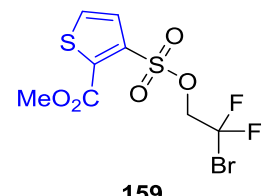

$$
\begin{gathered}
\mathrm{NBu}_{3}(1.5 \text { eq. }) \\
\frac{\mathrm{HCO}_{2} \mathrm{H}(1.5 \text { eq. })}{\left[\mathrm{Ru}(\mathrm{bpy})_{3} \mathrm{Cl}_{2} \cdot 6 \mathrm{H}_{2} \mathrm{O}(0.1 \mathrm{~mol} \%)\right.} \\
\mathrm{DMSO}(0.07 \mathrm{M}), \text { blue LED } \\
\mathrm{RT}, 1-16 \mathrm{~h}
\end{gathered}
$$

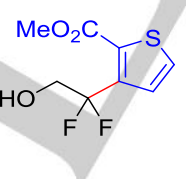

$160(89 \%)$

Scheme 50. The radical chain protonated Truce-Smiles aryl migration toward difluroaryl ethanols.

Brachet and Belmont applied photoredox catalysis to the carboamination of alkynes to form phthalazine derivatives 161 via a desulfonative hydroamination / Smiles rearrangement cascade (Scheme 51). ${ }^{[83]}$ Oxidation of the sulfonamide anion with $\mathrm{Ru}(\mathrm{bpy}){ }_{3} \mathrm{Cl}_{2}$ under visible light generates a sulfonaminyl radical, which undergoes 6 -exo-dig cyclization. The resultant alkenyl radical is then primed for a radical Smiles rearrangement to afford the final phthalazine products. Aryl and alkyl substituted alkynes are compatible with the reaction, except for a $p$ nitrophenyl example, and a one-pot two-step process was demonstrated in which initial condensation of the sulfonyl hydrazine and the requisite benzaldehyde, and then subjection to the photo-redox catalysis conditions, afforded the phthalazine products 162 in good yields.

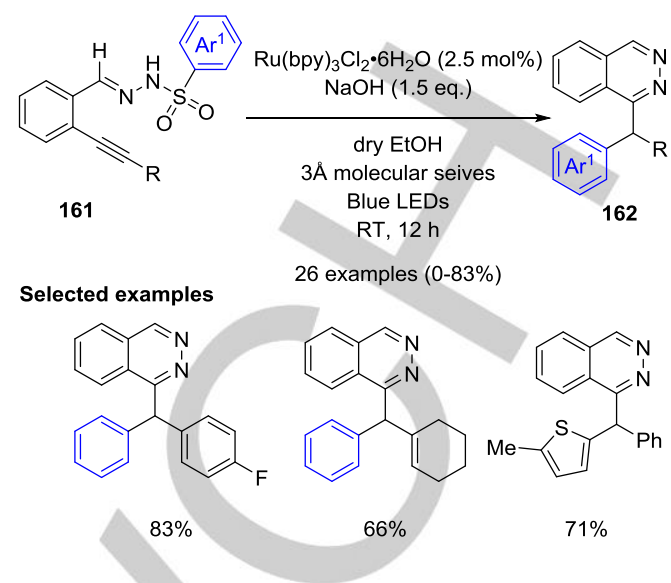

Scheme 51. Photoredox-catalyzed synthesis of phthalazines.

\section{Summary and Outlook}

The Smiles rearrangement has been revived in the recent literature as a method of preparing diverse sets of molecules containing aryl functionality. Recent progress in heteroatom arylation, in particular, has been a key enabling step for this chemistry, as $\mathrm{O}, \mathrm{N}$ and S-arylation can now be reliably achieved to set-up aryl transfer through Smiles processes. It is instructive to note that many of these arene transformations were unexpected discoveries, underlining the versatility of the Smiles rearrangement to take place under mild conditions without the requirement for special measures to prime substrates for ipsosubstitution. Indeed, the variation in the electronic character of migrating aryl groups is a powerful feature, with an extremely broad substrate range being accommodated across the various one and two electron systems.

The Truce-Smiles reaction has entered a new dimension whereby control of absolute stereochemistry can now be achieved through asymmetric lithiation chemistry. Exemplified by the Clayden rearrangement, a rich variety of $\mathrm{N}, \mathrm{O}$, and $\mathrm{S}$ functionality can be employed to direct the construction of secondary and tertiary benzylic stereocenters, fundamental features of pharmaceuticals and natural products. The application of asymmetric catalysis to this area is a potential challenge for the future.

Finally, the radical Smiles transformation has grown significantly with discoveries in radical generation unlocking some highly original bond constructions. The desulfonylative-Smiles reaction, where loss of sulfur dioxide drives the reaction forward, has been a particularly rich area of exploitation. Further discoveries can be expected in this area as mild precursors, and generative methods such as photoredox catalysis, enable new arene functionalizations using the Smiles transformation.

\section{Acknowledgements}

We thank the EPSRC for support. 
Keywords: Smiles • Rearrangements $\bullet$ ipso-substitution $\bullet$ arene $\bullet$ radical

[1] R. Henriques, Ber. Dtsch. Chem. 1894, 27, 2993-3005.

[2] a) O. Hinsberg, J. Prakt. Chem. 1914, 90, 345-353; b) O. Hinsberg, J. Prakt. Chem. 1916, 93, 277-301.

[3] a) L. A. Warren and S. Smiles, J. Chem. Soc. 1930, 1327-1331; b) A. Levi, L. A. Warren and S. Smiles J. Chem. Soc., 1933, 1490-1493; c) L. A. Warren and S. Smiles, J. Chem. Soc. 1930, 956-963; d) L. A. Warren and S. Smiles, J. Chem. Soc. 1932, 2774-2778; e) W. J. Evans and S. Smiles, J. Chem. Soc. 1935, 181-188; f) F. Galbraith and S. L. Smiles, J. Chem. Soc. 1935, 1234 1238; g) C. S. McClement and S. Smiles, J. Chem. Soc. 1937, 1016-1021. [4] W. E. Truce, E. M. Kreider and W. W. Brand, Organic Reactions 1970, 18, 99-215.

[5] a) I. Allart-Simon, S. Gérard and J. Sapi Molecules, 2016, 21, 878; b) Z.-M. Chen, X.-M. Zhang, and Y.-Q. Tu, Chem. Soc. Rev. 2015, 44, 5220-5245; c) T. J. Snape, Chem. Soc. Rev. 2008, 37, 2452-2458; d) K. Plesniak, A. Zarecki and J. Wicha, Top. Curr. Chem. 2007, 275, 163-250.

[6] a) W. E. Truce, W. J. Ray, O. L. Norman and D. B. Eickemeyer, J. Am. Chem. Soc. 1958, 80, 3625-3629; b) W. E. Truce and W. J. Ray, J. Am. Chem. Soc. 1959, 81, 481-484.

[7] J. F. Bunnett and T. Okamoto, J. Am. Chem. Soc. 1956, 78, 5363-5367 [8] a) M. Harfenist and E. Thom, J. Org. Chem. 1971, 36, 1171-1175; b) R. Bayles, M. C. Johnson, R. F. Maisey and R. W. Turner, Synthesis 1977, 3334.

[9] a) S. Sekiguchi and K. Okada, J. Org. Chem. 1975, 40, 2782-2786; b) C. F. Bernasconi, R. H. De Rossi and C. L. Gehriger, J. Org. Chem. 1973, 38, 28382842.

[10] C. F. Bernasconi and C. L. Gehriger, J. Am. Chem. Soc. 1974, 96, 1092 1099.

[11] K. Okada and S. Sekiguchi, J. Org. Chem. 1978, 43, 441-447.

[12] A. C. Knipe, J. Lound-Keast and N. Sridhar, J. Chem. Soc., Chem. Commun. 1976, 765.

[13] A. C. Knipe, N. Sridhar and J. Lound-Keast, Tetrahedron Lett. 1979, 20 2541-2544.

[14] A. C. Knipe and N. Sridhar, J. Chem. Soc., Chem. Commun. 1979, 791.

[15] M. O. Kitching, T. E. Hurst and V. Snieckus, Angew. Chem. Int. Ed. 2012, 51, 2925-2929.

[16] T. E. Hurst, M. O. Kitching, L. C. R. M. da Frota, K. G. Guimaraes, M. E. Dalziel and V. Snieckus, Synlett 2015, 26, 1455-1460.

[17] N. C. Ganguly, P. Mondal, S. Roy and P. Mitra, RSC Adv. 2014, 4, 5564055648.

[18] Y. Zhou, J. Zhu, B. Li, Y. Zhang, J. Feng, A. Hall, J. Shi and W. Zhu, Org. Lett. 2016, 18, 380-383.

[19] P. Sang, M. Yu, H. Tu, J. Zou and Y. Zhang, Chem. Commun. 2013, 49, 701-703.

[20] R. R. Nani, J. B. Shaum, A. P. Gorka and M. J. Schnermann, Org. Lett. 2015, 17, 302-305.

[21] S. S. Bhojgude, D. R. Baviskar, R. G. Gonnade and A. T. Biju, Org. Lett. 2015, 17, 6270-6273.

[22] L. El Kaïm, L. Grimaud and J. Oble, Angew. Chem. Int. Ed. 2005, 44, 7961-7964.

[23] L. El Kaïm and L. Grimaud, Eur. J. Org. Chem. 2014, 7749-7762.

[24] C. Aïssa, Eur. J. Org. Chem. 2009, 2009, 1831-1844.

[25] C. B. Jacobsen, M. Nielsen, D. Worgull, T. Zweifel, E. Fisker and K. A. Jørgensen, J. Am. Chem. Soc. 2011, 133, 7398-7404.

[26] M. Nielsen, C. Borch Jacobsen, M. W. Paixao, N. Holub and K. A. Jorgensen, J. Am. Chem. Soc. 2009, 131, 10581-10586.

[27] C. B. Jacobsen, L. Lykke, D. Monge, M. Nielsen, L. K. Ransborg and K. A. Jorgensen, Chem. Commun. 2009, 6554-6556.

[28] B. Pruger, G. E. Holmeister, C. B. Jacobsen, D. G. Alberg, M. Nielsen and K. A. Jorgensen, Chem. Eur. J. 2010, 16, 3783-3790.

[29] W. R. Erickson and M. J. McKennon, Tetrahedron Lett. 2000, 41, 45414544.

[30] L. H. Mitchell and N. C. Barvian, Tetrahedron Lett. 2004, 45, 5669-5671.

[31] T. J. Snape, Synlett 2008, 2689-2691.

[32] A. D. Alorati, A. D. Gibb, P. R. Mullens and G. W. Stewart, Org. Proc. Res. Dev. 2012, 16, 1947-1952.

[33] Y. Liu, X. Zhang, Y. Ma and C. Ma, Tetrahedron Lett. 2013, 54, 402-405. [34] D. Ameen and T. J. Snape, Eur. J. Org. Chem. 2014, 2014, 1925-1934.

[35] a) K. Okuda, H. Deguchi, S. Kashino, T. Hirota and K. Sasaki, Chem. Pharm. Bull. 2010, 58, 685-689; b) K. Okuda, N. Watanabe, T. Hirota and K.
Sasaki, Tetrahedron Lett. 2010, 51, 903-906; c) K. Okuda, T. Nikaido, T. Hirota and K. Sasaki, Synth. Commun. 2013, 43, 1619-1625; d) K. Okuda, J.-i. Takano, T. Hirota and K. Sasaki, J. Heterocycl. Chem. 2012, 49, 281-287. [36] J. R. Kosowan, Z. W'Giorgis, R. Grewal and T. E. Wood, Org. Biomol. Chem. 2015, 13, 6754-6765.

[37] a) E. Waldau and R. Pütter, Angew. Chem., Int. Ed., 1972, 11, 826-828; b) J. P. Gonzalez, M. Edgar, M. R. J. Elsegood and G. W. Weaver, Org. Biomol. Chem. 2011, 9, 2294-2305.

[38] O. K. Rasheed, I. R. Hardcastle, J. Raftery and P. Quayle, Org. Biomol. Chem. 2015, 13, 8048-8052.

[39] C. M. Holden, S. M. A. Sohel and M. F. Greaney, Angew. Chem. Int. Ed. 2016, 55, 2450-2453.

[40] M. W. Wilson, S. E. Ault-Justus, J. C. Hodges and J. R. Rubin, Tetrahedron 1999, 55, 1647-1656.

[41] T. Fukuyama, C.-K. Jow and M. Cheung, Tetrahedron Lett. 1995, 36, 6373-6374.

[42] V. Lupi, M. Penso, F. Foschi, F. Gassa, V. Mihali and A. Tagliabue, Chem. Commun. 2009, 5012-5014.

[43] F. Foschi, D. Landini, V. Lupi, V. Mihali, M. Penso, T. Pilati and A Tagliabue, Chem. - Eur. J. 2010, 16, 10667-10670.

[44] a) V. Gimenez-Navarro, T. Volna and V. Krchňák, ACS Comb. Sci. 2015 17, 433-436; b) P. Smyslova, K. Kisseljova and V. Krchňák, ACS Comb. Sci. 2014, 16, 500-505.

[45] J. H. Fan, J. Yang, R. J. Song and J. H. Li, Org Lett 2015, 17, 836-839. [46] S. Coulibali, T. Godou and S. Canesi, Org. Lett. 2016, 18, 4348-4351.

[47] C. Dey, D. Katayev, K. E. O. Ylijoki and E. P. Kündig, Chem. Commun. 2012, 48, 10957-10959.

[48] M. Getlik, B. J. Wilson, M. M. Morshed, I. D. G. Watson, D. Tang, P. Subramanian and R. Al-awar, J. Org. Chem. 2013, 78, 5705-5710.

[49] J. Clayden, Lithium Compounds in Organic Synthesis, ed R. Luisi and V. Capriati, Wiley-VCH, 2014, ch 13, pp. 375-394.

[50] J. Clayden, J. Dufour, D. M. Grainger and M. Helliwell, J. Am. Chem. Soc. 2007, 129, 7488-7489.

[51] J. Clayden and U. Hennecke, Org. Lett. 2008, 10, 3567-3570.

[52] J. Clayden, R. Bach and U. Hennecke, Synlett 2009, 2009, 421-424.

[53] D. J. Tetlow, U. Hennecke, J. Raftery, M. J. Waring, D. S. Clarke and J. Clayden, Org. Lett. 2010, 12, 5442-5445.

[54] M. B. Tait, P. A. Ottersbach, D. J. Tetlow and J. Clayden, Org. Proc. Res Dev. 2014, 18, 1245-1252.

[55] R. C. Atkinson, D. J. Leonard, J. Maury, D. Castagnolo, N. Volz and J. Clayden, Chem. Commun. 2013, 49, 9734-9736.

[56] K. Tomohara, T. Yoshimura, R. Hyakutake, P. Yang and T. Kawabata, J. Am. Chem. Soc. 2013, 135, 13294-13297.

[57] R. C. Atkinson, F. Fernandez-Nieto, J. Mas Rosello and J. Clayden, Angew. Chem. Int. Ed. 2015, 54, 8961-8965.

[58] J. Maury and J. Clayden, J. Org. Chem. 2015, 80, 10757-10768.

[59] M. B. Tait, S. Butterworth and J. Clayden, Org. Lett. 2015, 17, 1236-1239.

[60] J. Clayden, W. Farnaby, D. M. Grainger, U. Hennecke, M. Mancinelli, D.

J. Tetlow, I. H. Hillier and M. A. Vincent, J. Am. Chem. Soc. 2009, 131, 34103411.

[61] A. M. Fournier, R. A. Brown, W. Farnaby, H. Miyatake-Ondozabal and J. Clayden, Org. Lett. 2010, 12, 2222-2225.

[62] P. MacLellan and J. Clayden, Chem. Commun. 2011, 47, 3395-3397.

[63] G. Mingat, P. MacLellan, M. Laars and J. Clayden, Org. Lett. 2014, 16, 1252-1255.

[64] J. Clayden, M. Donnard, J. Lefranc, A. Minassi and D. J. Tetlow, J. Am Chem. Soc. 2010, 132, 6624-6625.

[65] M. Tait, M. Donnard, A. Minassi, J. Lefranc, B. Bechi, G. Carbone, P O'Brien and J. Clayden, Org. Lett. 2013, 15, 34-37.

[66] A. M. Fournier and J. Clayden, Org. Lett. 2012, 14, 142-145.

[67] D. Castagnolo, D. J. Foley, H. Berber, R. Luisi and J. Clayden, Org. Lett. 2013, 15, 2116-2119.

[68] D. Castagnolo, L. Degennaro, R. Luisi and J. Clayden, Org. Biomol. Chem. 2015, 13, 2330-2340.

[69] D. J. Tetlow, M. A. Vincent, I. H. Hillier and J. Clayden, Chem. Commun. 2013, 49, 1548-1550.

[70] D. M. Grainger, A. Campbell Smith, M. A. Vincent, I. H. Hillier, A. E. H. Wheatley and J. Clayden, Eur. J. Org. Chem. 2012, 2012, 731-743.

[71] A. M. Fournier, C. J. Nichols, M. A. Vincent, I. H. Hillier and J. Clayden, Chem. Eur. J. 2012, 18, 16478-16490. 
[72] M. A. Vincent, J. Maury, I. H. Hillier and J. Clayden, Eur. J. Org. Chem. 2015, 2015, 953-959.

[73] T. Zhou, F.-X. Luo, M.-Y. Yang and Z.-J. Shi, J. Am. Chem. Soc. 2015, 137, 14586-14589.

[74] a) R. Loven and W. N. Speckamp, Tetrahedron Lett. 1972, 13, 15671570; b) J. J. Köhler and W. N. Speckamp, Tetrahedron Lett. 1977, 18, 631 634.

[75] a) W. B. Motherwell and A. M. K. Pennell, J. Chem. Soc., Chem. Commun. 1991, 877; b) M. L. E. N. da Mata, W. B. Motherwell and F. Ujjainwalla, Tetrahedron Lett. 1997, 38, 141-144.

[76] M. Pudlo, I. Allart-Simon, B. Tinant, S. Gerard and J. Sapi, Chem. Commun. 2012, 48, 2442-2444.

[77] W. Kong, M. Casimiro, E. Merino and C. Nevado, J. Am. Chem. Soc. 2013, 135, 14480-14483.

[78] a) W. Kong, N. Fuentes, A. Garcia-Dominguez, E. Merino and C. Nevado, Angew. Chem. Int. Ed. 2015, 54, 2487-2491; b) N. Fuentes, W. Kong, L.
Fernandez-Sanchez, E. Merino and C. Nevado, J. Am. Chem. Soc. 2015, 137, 964-973; c) W. Kong, E. Merino and C. Nevado, Angew. Chem. Int. Ed. 2014 53, 5078-5082.

[79] G. Zheng, Y. Li, J. Han, T. Xiong and Q. Zhang, Nat. Commun. 2015, 6 7011.

[80] S. W. Crossley, R. M. Martinez, S. Guevara-Zuluaga and R. A. Shenvi, Org. Lett. 2016, 18, 2620-2623.

[81] J. J. Douglas, H. Albright, M. J. Sevrin, K. P. Cole and C. R. J. Stephenson, Angew. Chem. Int. Ed. 2015, 54, 14898-14902.

[82] J. J. Douglas, M. J. Sevrin, K. P. Cole and C. R. J. Stephenson, Org Proc. Res. Dev. 2016, 20, 1148-1155

[83] E. Brachet, L. Marzo, M. Selkti, B. König and P. Belmont, Chem. Sci. 2016, 7, 5002-5006. 


\section{Entry for the Table of Contents}

\section{MINIREVIEW}

\section{Modern Aspects of the Smiles}

\section{Rearrangement}

The Smiles rearrangement is a powerful tool for arene functionalization. The reaction is enjoying renewed attention, as recent developments in mild $\mathrm{C}-\mathrm{X}$ and $\mathrm{C}-\mathrm{C}$ bond formation are harnessed for creative arene syntheses. Focusing on the recent literature, this minireview discusses advances in Smiles chemistry in both the polar and radical regimes.

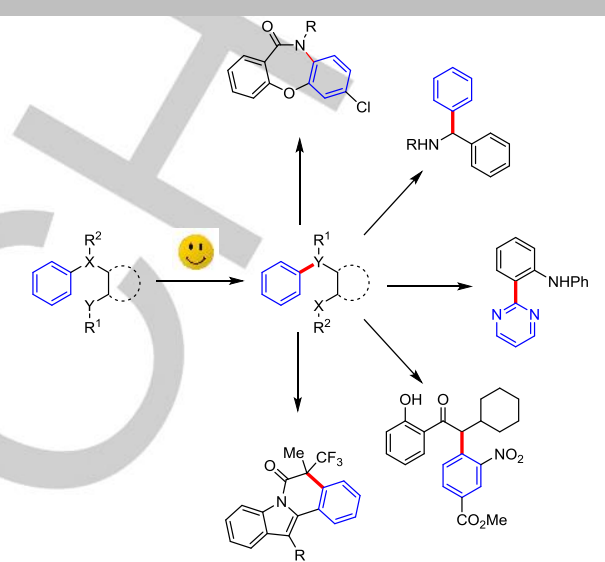

Catherine M. Holden and Michael $F$.

Greaney*

Page No. - Page No.

Modern Aspects of the Smiles

Rearrangement 